\title{
Yapay Sinir Ağları Kullanılarak Fotovoltaik Panel Güç Çıkışlarının Tahmini ve Sezgisel Algoritmalar ile Karşılaştırılması
}

\author{
Emre Dand $11^{1 *}$, Erol Gürgen ${ }^{2}$ \\ ${ }^{1}$ Bilecik Şeyh Edebali Üniversitesi, Mühendislik Fakültesi, Bilgisayar Mühendisliği Bölümü, Bilecik (ORCID: 0000-0001-6559-1399) \\ 2 Bilecik Şeyh Edebali Üniversitesi, FBE, Elektronik ve Bilgisayar Mühendisliği Anabilim Dalı, Bilecik (ORCID: 0000-0003-3403-9002)
}

(Illk Geliş Tarihi 14 Mart 2019 ve Kabul Tarihi 8 Mayıs 2019)

(DOI: 10.31590/ejosat.540262)

ATIF/REFERENCE: Dandıl, E., \& Gürgen, E. (2019). Yapay Sinir Ağları Kullanılarak Fotovoltaik Panel Güç Çıkışlarının Tahmini ve Sezgisel Algoritmalar ile Karşılaştııılması. Avrupa Bilim ve Teknoloji Dergisi, (16), 146-158.

\begin{abstract}
$\ddot{O} \mathbf{z}$
Fotovoltaik(FV) paneller, güneş ışığından elektrik enerjisi elde etmek için kullanılan sistemlerdir. Farklı zamanlarda FV sistemlerden üretilen güç değerlerinin tahmini güneş panellerinin güvenilir bir enerji kaynağı olarak efektif kullanılması ve ekonomik kullanılması açıssından gereklidir. Güneş panellerinden üretilen çıkış gücünün kestirimi aynı zamanda, güneş panellerinin kurulumu, elektrik şirketlerine rehberlik etmesi, enerjinin yönetimi ve dağıtılması ve bunun yanında en kısa sürede optimum enerjiyi elde edebilir hale gelmek ve maksimum üretim kapasitesi ulaşmaya yönelik gerekli panel adaptasyonlarının tespit edilmesi için gerekli zamandan kazanç; ek iş̧̧ilik maliyetlerinin azaltılması anlamında büyük önem arz etmektedir Bu çalışmada, FV panellerinden elde edilen güç değerlerinin aylık olarak tahmini için farklı algoritmalar ile öğrenebilen Yapay Sinir Ağları(YSA) kullanılmıştır. Altı farklı açısal konuma yerleştirilen panellerden elde edilen güç değerlerinin tahmin edilmesinde, geleneksel yöntemlere göre daha iyi sonuç veren Parçacık Sürü Optimizasyonu(PSO) optimizasyon algoritmasına dayalı YSA ile Geriye Yayılım(GY) ve bir diğer optimizasyon algoritması olan Klonal Seçim Algoritması(KSA) ile eğitilen YSA modellerinden yararlanılmıştır. Tahmin sonuçlarının doğrulanmasında üç popüler istatiksel değerlendirme kriteri olan Ortalama Mutlak Yüzde Hata (MAPE), Ortalama Karesel Hataların Karekökü (RMSE) ve Varyans $\left(\mathrm{R}^{2}\right)$ eşitliklerinden yararlanılmıştır. Her üç kriterlerden elde edilen doğrulama sonuçları incelendiğinde, hemen hemen tüm aylar için PSO algoritması ile eğitilen YSA yapısının, KSA ve GY algoritmaları ile eğitilen YSA yapılarına göre daha başarılı olduğu görülmüştür. Bazı sonuçlarda ise GY ile eğitilen YSA yapısının, PSO ile eğitilen YSA yapısına göre, sonuçlar birbirine yakın olmakla birlikte daha başarılı olduğu anlaşılmışır.
\end{abstract}

\section{Prediction of Photovoltaic Panel Power Outputs using Artificial Neural Networks and Comparison with Heuristic Algorithms}

\begin{abstract}
The prediction of power outputs generated from photovoltaic (PV) systems at different times is necessary for reliable and economical for use of solar panels. The prediction of the power output is also very important in terms of factors such as installation of solar panels, guidance of electricity companies, energy management and distribution. Determination of optimum solar panel positions and angles, providing energy productivity to maximize production capacity in a short time period is the most time consuming job for regulations for a companies. Also, adaptation of panels increases costs. Therefore, new and healthy prediction methods have a great importance to minimize these work force costs. In this study, Artificial Neural Network (ANN) model learned by heuristic algorithms
\end{abstract}

\footnotetext{
* Sorumlu Yazar: Bilecik Şeyh Edebali Üniversitesi, Mühendislik Fakültesi, Bilgisayar Mühendisliği Bölümü, Bilecik, Türkiye, ORCID: 0000-00016559-1399, emre.dandil@bilecik.edu.tr
} 
are used for the prediction of power outputs obtained from PV panels monthly. Particle Swarm Optimization (PSO), BackPropagation (BP), Clonal Selection Algorithm (CSA) are used to train ANN to predict six different PV panel located in different angles from 10 to 60 degrees. Three different popular evaluation methods which are called mean absolute percentage error (MAPE), root mean square error (RMSE), varyans $\left(\mathrm{R}^{2}\right)$ used to do comparison. According to examination of verification results, PSO is almost most successful algorithm as a training method when it is compared with BP and CSA. It is seen for the some of the results belong to a few months that BP is slightly better than PSO.

Keywords: Photovoltaic Panel, Power Prediction, ANN, Back-propagation; PSO, Clonal Selection Algorithm

\section{Giriş}

Dünyada ve onun küçük bir yansıması olarak Türkiye'de; gelişen teknoloji beraberinde aynı oranda artan bir enerji ihtiyacını ortaya çıkarmaktadır. Bu ihtiyacın giderilmesi için kullanılan kaynaklar incelendiğinde, bölgesel olarak farklılıklar olsa da fosil yakıt türlerinin ön plana çıktığı görülmektedir. Türkiye’ye ait yıllık istatistikler incelendiğinde enerji ihtiyacının \%66.7'si fosil yakıtlardan, $\% 25.3^{\prime}$ ü hidrolikten, \%8.1' $\mathrm{i}$ ise jeo-termal, rüzgar, güneş enerjisi ve diğer kaynaklardan elde edilmektedir[1,2]. Gelişen ihtiyaçlara cevap verebilmek adına devletler mevcut politikalarını gözden geçirerek, gerek tükenme olasılığı, gerekse çevreye etkileri düşünülerek fosil yakıtlara alternatif olan enerji kaynaklarını ve üretim yöntemlerini araştırmaya başlamışlardır.

Elektrik enerjisi elde etmek için kullanılan yöntemlerden birisi de FV paneller yardımıyla güneş enerjisinden yararlanmaktır. Özellikle güneş enerjisi, diğer enerji kaynaklarına göre temiz, sessiz, ekonomik, güvenilir ve tükenmez olması nedeniyle son zamanlarda daha da önemli hale gelmiştir [3]. FV panellerden üretilen enerji, coğrafi konum, mevsimsel değişimler ve çevresel koşullar gibi faktörlere göre değişiklikler gösterebilmektedir. Buna bağlı olarak FV panellerin eğim açısının aylık, mevsimsel ve yıllık olarak değiştirilmesi ile panellerden en yüksek gücün elde edilmesi sağlanabilmektedir. Güncel ve modern güç sistemlerinin güvenli ve ekonomik olarak işletilmesi için üretim planlamaları gerçek zamanlı, günlük, haftalık, aylık ve yıllık olarak yapılabilmektedir. Bundan dolayı, FV panel istasyonları gibi yenilenebilir güç tesislerinin güç çıkış değerlerinin ve yük eğilimlerinin kestirilmesi temel bir süreç olarak ortaya çıkmaktadır.

Solar güç istasyonlarının verimliliğinin(çıkış gücü), farklı hava koşullarına göre değişimler gösterdiği bilinen bir gerçektir. Bu nedenden dolayı, son zamanlarda FV panellerin güç çıkış değerlerinin tahmin edilmesine yönelik çalışmaların önemli ölçüde arttığı görülmektedir. Günümüzde FV panellerin güç tahmini için yaygın olarak kullanılan iki temel yaklaşım bulunmaktadır [4]. Bunlardan birincisi, solar ışınım, ortam sıcaklığı ve matematiksel modelleri kullanılarak elde edilen bazı parametreler gibi çevresel parametrelerin tahmini yardımıyla FV sistemlerindeki aktif gücün hesaplanmasıdır. Diğeri ise, FV sistemlerin aktif güç çıkışlarının doğrudan tahmin edilmesidir [5]. Solar 1şınım verilerinin saatlik olarak tahmin edilmesi çok zor olduğundan dolayı, Kudo vd.[5]' un çalışmasında aktif güç çıkışı, daha önce ölçülen akım ve gerilim verilerine bağlı olarak doğrudan tahmin edilmiştir.

Literatürde, şimdiye kadar FV panel güç çıkışlarının tahmini için birçok yöntem önerilmiştir. Lorenz vd. [4] ve Kudo vd. [5] hava durumu verileri kullanarak FV panel güç çıkış karakteristiklerini ortaya koyan, çoklu doğrusal regresyon yöntemleri ve YSA modelleri kullanılarak elde edilen solar 1şınım tahminlerini karşılaştırmalı birer çalışma ile sunmuşlardır. Junseok vd. [6] ve Li vd. [7], Markov zincirleri kullanarak olasılıksal bir yaklaşım ile Fotovoltaik üretim merkezlerinde enerji depolama birimleri üzerine çalışma yapmışlardır. Ran vd. [8] ve Shi vd. [9] ise çalışmalarında, bir makine öğrenmesi yöntemi olan Destek Vektör Makineleri ile FV panel güç çıkışlarının tahmin edilmesine yönelik çalışmalar yürütmüşlerdir. Wang [10] çalışmasında, yukarıdaki çalışmaların dışında, FV güç çıkışlarının tahmin edilmesinde en uygun metodun YSA olduğu bazı çalışmalarda ortaya koymuştur. Kou vd. [11] çalışmalarında, GY kullanarak eğitilen YSA yapısı ile meteoroloji verilerinin de kullanılması sayesinde solar panel çıkış gücü tahmini yapmışlardır. Zhang vd. [12], PSO evrimsel algoritmasını hibrit bir yöntem haline getirerek yapay sinir a ğını eğittikleri çalışmalarında, ışınım değerlerini de girdi olarak kullanmış ve solar radyasyon tahmin çıkarımları elde etmişlerdir. Qasrawi [13], farklı bölgelere yerleştirilen güneş panellerinden alınan panel çıktıları ve uydulardan alınan veriler ile birlikte çok katmanlı ve GY (LevenbergMarquardt) ile eğitilmiş YSA tasarlamışlardır. Sisteme girdi olarak nem, solar 1şınım, gün ışı süresi uzunluğu, bulutsuz hava şartları verilmiştir. Test verileri ile ağın başarımı doğrulanmıştır. Zhu vd. [14], dalgacık dönüşümü(wavelet transform) yöntemi ile verilere indirgeme uygulamışlardır. Bu verileri YSA’nın eğitiminde kullandıkları hibrit bir yöntem çalışmasının ardından tekrar dalgacık ayrıştırması Yöntemi ile veriyi yapılandırma işlemine tabi tutmuşlar ve mevcut YSA çalışmalarına oranla daha az matematiksel işlem gerektiren bir çalışma ortaya çıkarmışlardır. Prokop vd. [15], ANFIS ve çok katmanlı algılayıcı (MLP) yöntemler ile bir çalışma önermişlerdir. ANFIS ve MLP'nin benzer davranışlar sergileyerek ortalama \%2 lik bir kesinlikte tutarlı sonuçlar elde etmişlerdir. ANFIS'in MLP'ye nazaran daha kesin sonuçlar verdiklerini çalışmalarında belirtmişlerdir. Paulin ve Praynlin [16], güneş panellerinde ortalama ortam 1sıs1, ortalama panel 1sısı, dönüştürücü ortalama 1sısı, solar 1şınım, rüzgar hızı ve güç çıkış1 verilerini girdi olarak kullanarak GY tabanlı YSA'yı eğittikleri karşılaştırmalı bir çalışma ortaya koymuşlardır. Rana vd. [17], farklı YSA yapılarından oluşan bir iteratif ve iteratif olmayan iki farklı yöntemin vermiş olduğu sonuçları karşılaştırarak iteratif olan yöntemin diğerlerine göre yakın sonuçlar verdiğini göstermişlerdir.

Bu çalışmada ise geriye yayılım gibi klasik algoritmalardan farklı olarak sezgisel yöntemler kullanılarak eğitilen bir YSA modeli ile farklı eğim açılarına $(100,200,300,400,500,600)$ yerleştirilmiş FV panel güç çıkışlarının, akım ve gerilim değerlerine bağlı bir şekilde aylık olarak tahmin edilmesine yönelik hibrit bir yöntem önerilmiştir. Önerilen bu çalışmada, geriye yayılım algoritması yardımıyla elde edilen güç değerleri ile sezgisel yöntemler olan PSO ve KSA sezgisel algoritmaları ile elde edilen güç değerlerinin karşılaştırılmalı değerlendirmesi de yapılmıştır. Ayrıca, yöntemin elde edilen sonuçlar üzerindeki etkinliği ölçüm yapılan gerçek ve tahmin edilen değerler arasındaki ortalama yüzdelik hatanın analizi ile doğrulanmıştır. Çalışmanın sonraki aşamaları şu şekilde organize edilmiştir. İkinci bölümde deneysel düzenek ve veriseti ile kullanılan algoritmalar çalışmanın materyal ve metot kısmı olarak 
sunulmuştur. Üçüncü bölümde deneysel çalışmalar ve elde edilen bulgular detaylı olarak analiz edilmiş ve son bölümde ise sonuçlar tartışılmıştır.

\section{Materyal ve Metot}

\subsection{Deneysel Düzenek ve Veriseti}

Bu çalışmada kullanılan veriler Bilecik Şeyh Edebali Üniversitesi yerleşkesi içerisine kurulan ve Şekil 1' de görülen FV panel test düzeneğinden elde edilmiştir [3]. Düzeneğe yerleştirilen her bir FV panel Perlight marka ve PLM-100P/12 model olup polikristal yapıya sahiptir. Deney düzeneğinde $10^{\circ}, 20^{\circ}, 30^{\circ}, 40^{\circ}, 50^{\circ}, 60^{\circ}$ olmak üzere farklı eğim açılarına yerleştirilen $\mathrm{FV}$ panelin gerilim değerleri gün boyunca ölçülmüsşür. Ölçülen analog veriler mikrodenetleyici ile sayısal verilere dönüştürülmüştür. Daha sonra Raspberry Pi kullanılarak sayısal verilerin her 10 dakikada bir ortalaması alınarak saklanması sağlanmıştır. Her bir FV panelden ölçülen gerilim, akım ve güç gibi elektriksel verilerin toplanması, kayıt altına alınması ve analiz çalışmaları Raspberry Pi üzerine kurulu bir web sunucusu sayesinde gerçekleştirilmiştir. Böylece sistemin günün her saatinde takip edilebilmesi olanağı da bulunmaktadır.

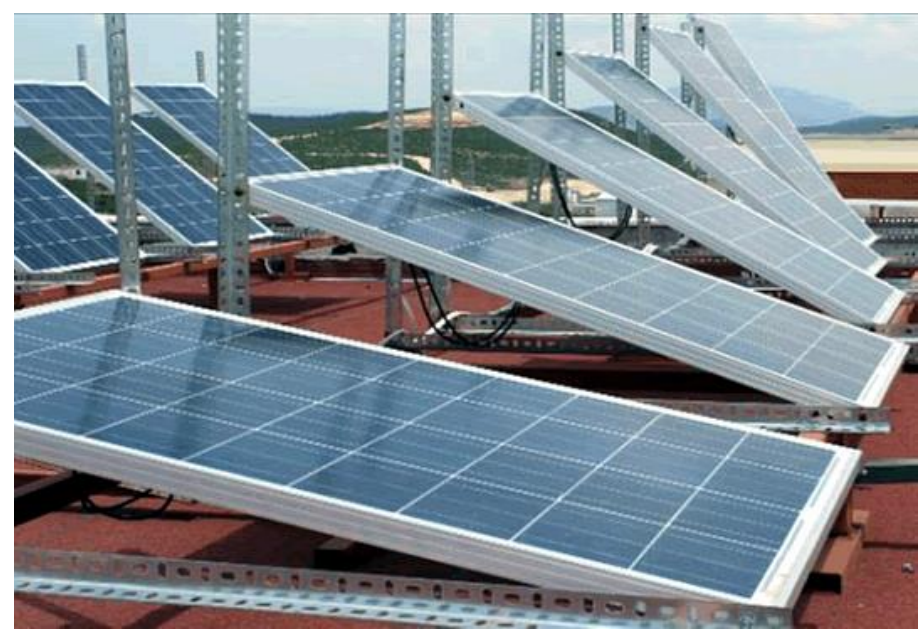

Şekil 1. FV panel deney düzeneği [3]

Yatay düzlemde $10^{\circ}$ ile $60^{\circ}$ arasında değişen farklı açılarda konumlandırılmış FV panellerden elde edilen akım, gerilim ve güç verileri Mayıs 2015-Mayıs 2016 tarihleri arasında bir yıl süre ile kaydedilmiş ve izlenmiştir. Şekil 2' de farklı açılara yerleştirilen her bir panelden 1 Ağustos 2015 tarihinde bir gün boyunca ölçülen akım, gerilim ve güç değerleri görülmektedir. Ağustosun yaz ayı olması nedeniyle akım, gerilim ve güç değerlerinin yüksek olduğu görülmektedir.

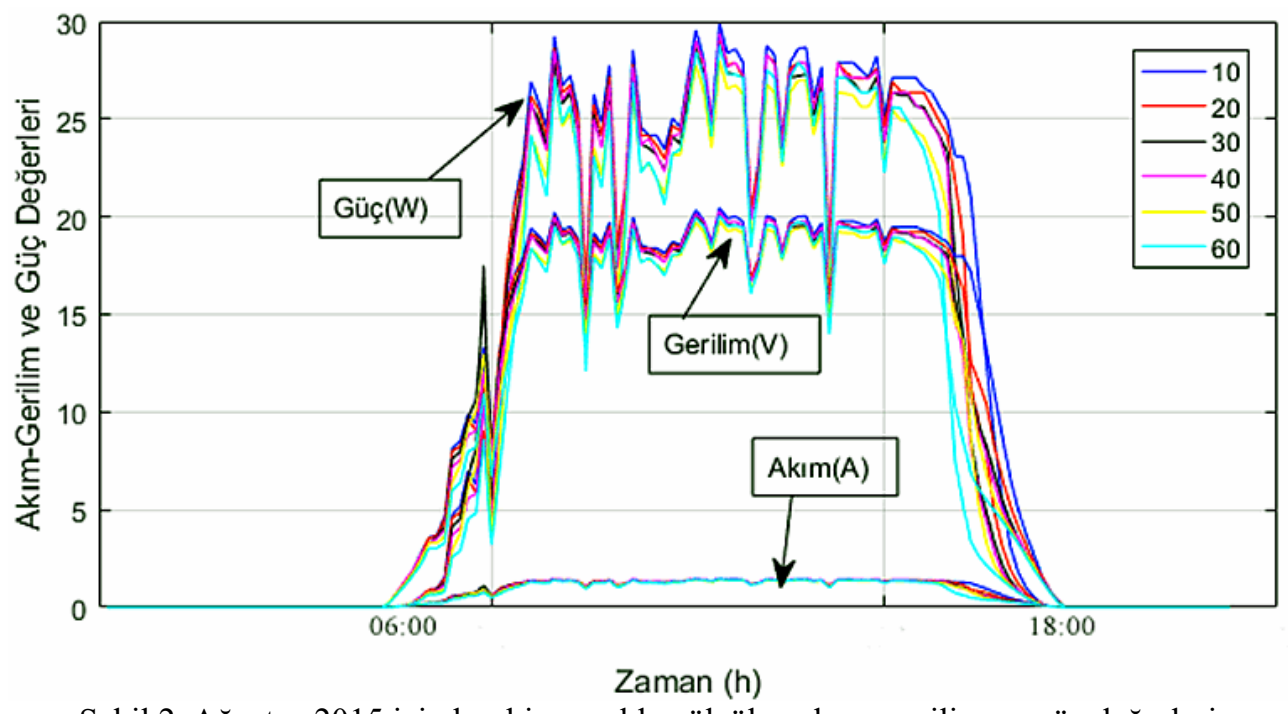

Şekil 2. Ağustos 2015 için her bir panelden ölçülen akım, gerilim ve güç değerleri

Şekil 3' ta Ağustos 2015 için, 6 farklı panelin her birisinden bir ay boyunca deney düzeneğinden elde edilen akım, gerilim ve güç değerleri grafik üzerinde gösterilmiştir. Bu değerlerden de görüleceği üzere Ağustos ayı için panellerden elde edilen güç değerleri yüksek seviyede seyretmektedir. 


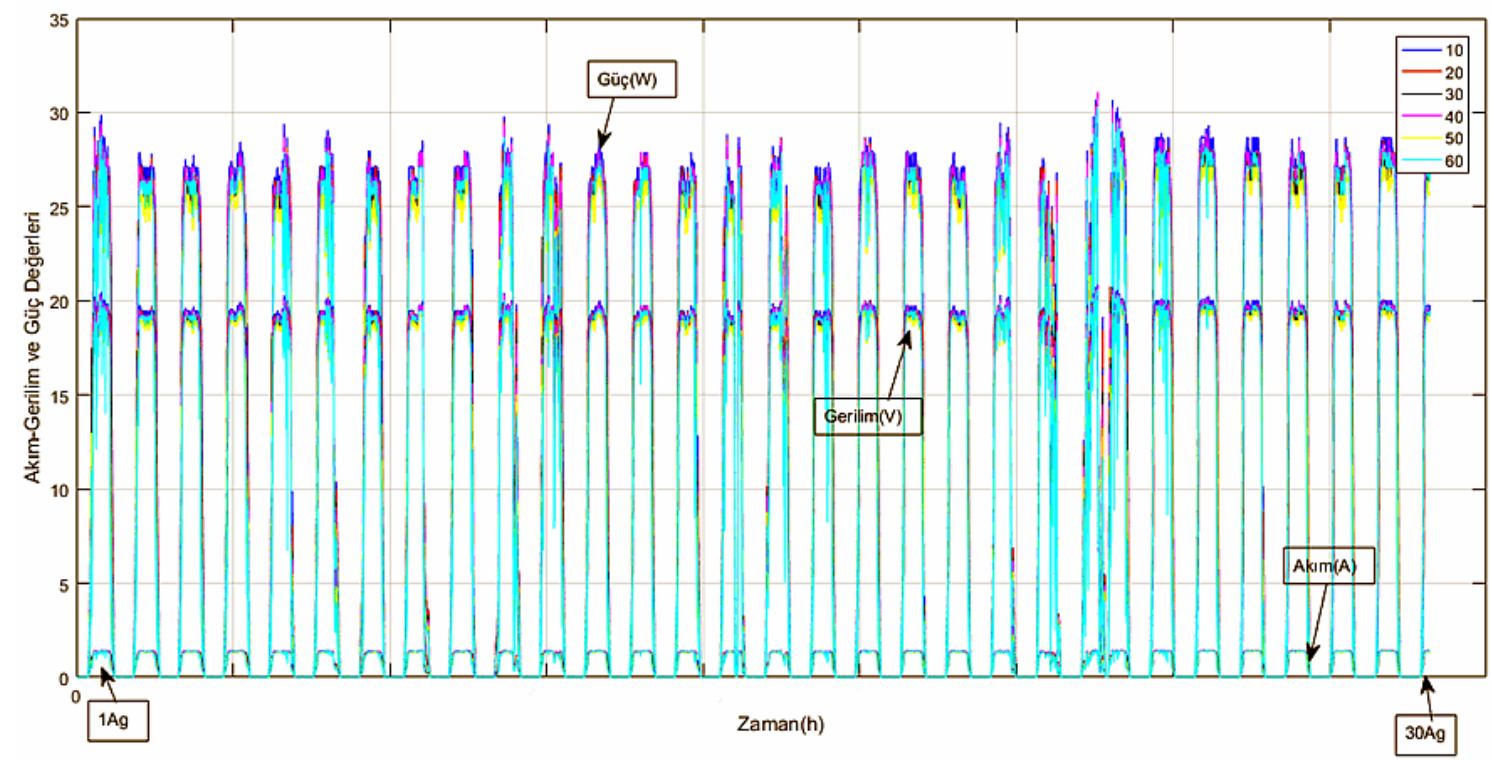

Şekil 3. Ağustos 2015 için yaklaşık bir ay boyunca her bir panelden ölçülen akım, gerilim ve güç değerleri

Deneysel düzenekten alınan veriler, ağın eğitimi için kullanılmadan önce indirgeme işlemi yapılmıştır. Özellikle aydınlanma süreleri farklı olan yaz ve kış ayları için farklı olacak örnekleme sayıları, günün aynı saat dilimlerinde $06^{00}-18^{00}$ arasına eşitlenmiş ve ağın eğitimi için günlük aynı örnekleme sayısı elde edilmiştir. Bu çalışmada aylık olarak FV panel güç çıkışlarının tahmini yapıldığı için, her ayın her günü için ilgili saat aralıklarında ölçülen akım ve gerilim değerlerinin günlük ortalama değerleri hesaplanarak aylık ölçümler elde edilmiştir. Şekil 4' te Ağustos 2015 için $06^{00}-18^{00}$ arasında gün boyunca ortalamaları alınan akım, gerilim ve güç değerleri gösterilmektedir. Ağustosun yaz ayı olması, güneşli gün sayısının fazla olması ve güneş ışınlarının daha dik gelmesi ile üretilen akım, gerilim ve hesaplanan güç değerlerinin yüksek olduğu görülmektedir.

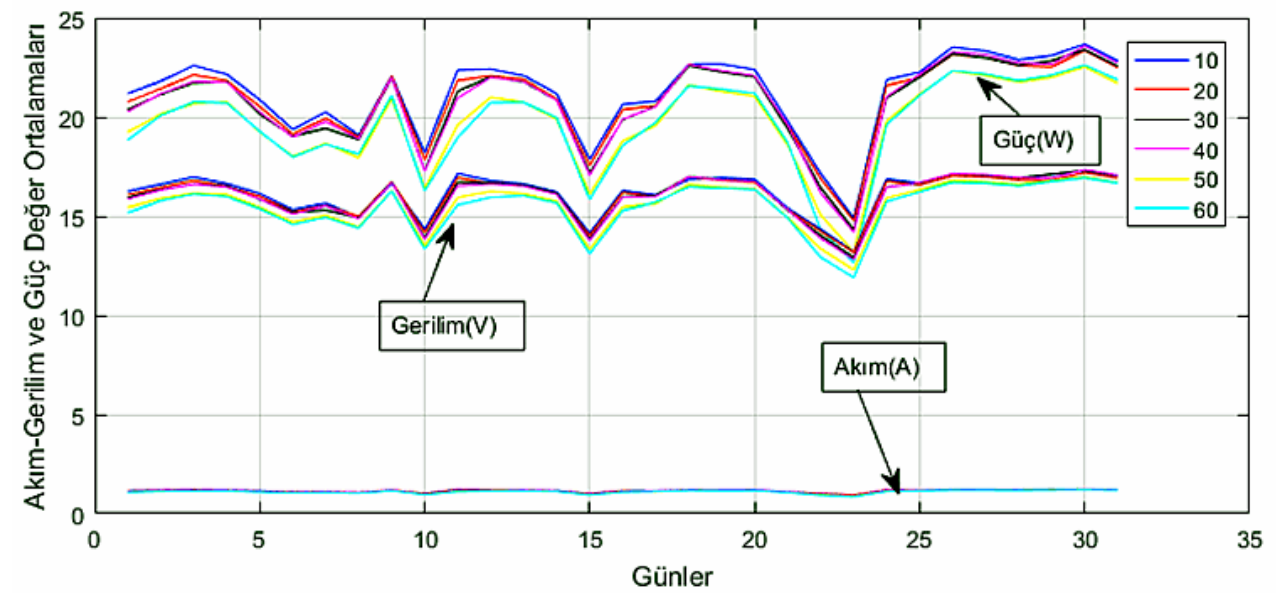

Şekil 4. Ağustos 2015 için ortalama akım, gerilim ve güç değerleri

Tüm aylar için $06^{00}-18^{00}$ arasında gün boyunca elde edilen ortalama güç verilerine ait örüntü grafikleri Şekil 5' te gösterilmiştir. $\mathrm{Bu}$ grafikler incelendiğinde; güç eğrilerinin benzer eğilimler gösterdikleri, fakat açısal değerlere göre nicelik farklarının ortaya çıktığı görülmektedir. Aynı zamanda mevsimsel değişimlere bağlı güneşin konum ve hareketinde meydana gelen değişikliklerinde paneller üzerinde ortaya çıkardığı üretim farklılıkları görülebilmektedir. Grafiğe bakılarak mevsimlere bağlı olarak panellerde yapılacak açısal adaptasyonların, verimi artırma yönünde pozitif etki edeceği kanısına da varılabilmektedir. 

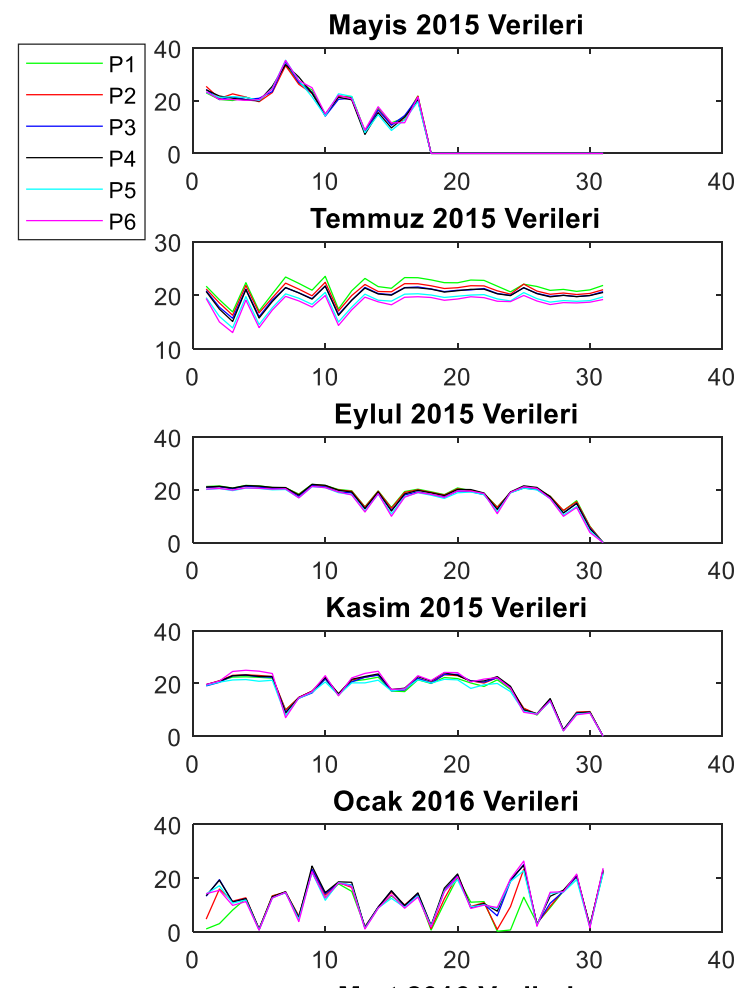

Mart 2016 Verileri
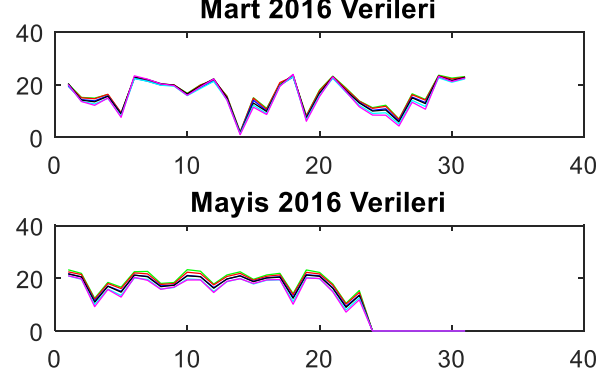
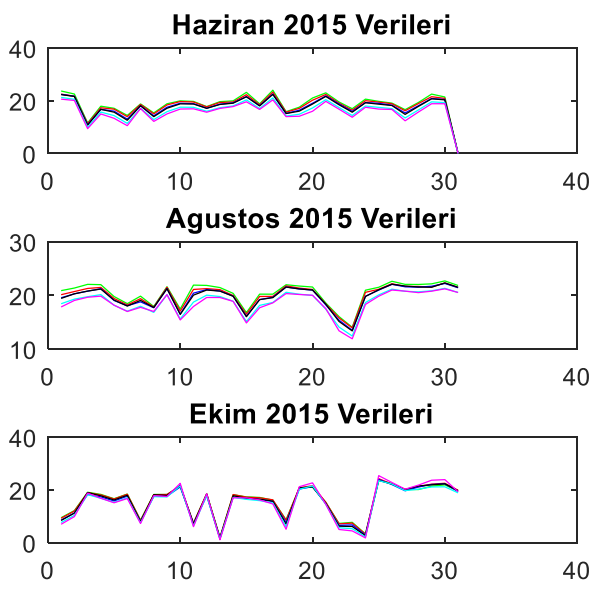

Aralik 2015 Verileri

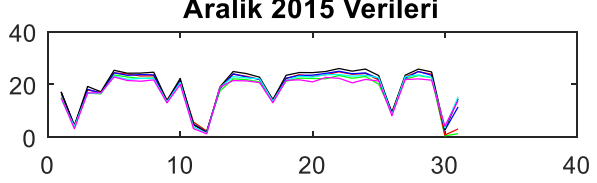

Subat 2016 Verileri

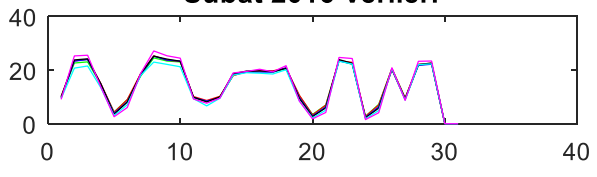

Nisan 2016 Verileri

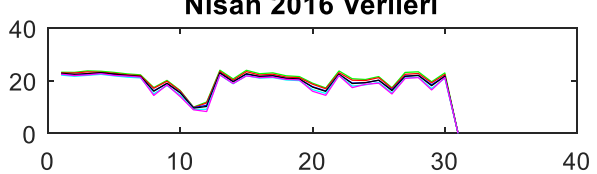

Şekil 5. Tüm aylara ait ortalama güç örüntülerine ait grafikler

\subsection{Yapay Sinir Ăgları}

Yapay sinir ağları(YSA) insan sinir sisteminin işleyiş yapısını modelleme fikrine dayalı olarak ortaya çıkan ve çok sayıda sinir hücresinin birbirine bağlanarak oluşturduğu öğrenme şeklini referans alan yapay zeka yöntemlerinden birisidir. Bunun yanında sınıflandırma, tahmin yapma, kestirim gibi problemlerde geniş olarak kullanılan etkili ve danışmanlı bir öğrenme metodudur. Günümüzde yapay sinir ağları kullanan sistemler, genellikle çok katmanlı ileri beslemeli ağ modelini ve ağın eğitilmesi için ise geriye yayılım algoritmasını kullanmaktadır [11]. Bu çalışmada da, çok katmanlı ileri beslemeli bir ağın ağırlıklarını hem GY hem de sezgisel algoritmalar olan PSO ve KSA yöntemleri ile belirleyen bir YSA yapısı kullanılmış̧ır. Üç katmanlı ve ileri beslemeli bir YSA' nın temel yapısı Şekil 6' da gösterilmiştir. Önerilen YSA modeli giriş, gizli ve çıkış olmak üzere üç katmandan oluşmaktadır. Giriş katmanı akım ve gerilim olmak üzere 2 nörona sahipken, çıkış katmanında ise güç olmak üzere 1 tane nöron bulunmaktadır. Gizli katman ise 3 tane nörona sahiptir. Gizli katmandaki nöron sayısı problemin özelliğine göre değişiklik göstermektedir. Bu problemde ağın gizli katmanında yer alan 3 nöron ile yeterli ve en iyi performansı sağladığı görülmüştür. Eğitim sonrasında $\mathrm{V}$ (gerilim) ve $\mathrm{A}(\mathrm{akım})$ ağa verildiğinde $\mathrm{P}($ güç çıkışını) tahmin edebilir duruma gelmektedir. Ağın performansı Eşitlik 1' de gösterilen Ortalama Karesel Hataya(MSE) göre hesaplanmıştır. Burada, $h$ değeri $i$. örüntünün ağa sürülmesi sonrasında oluşan gerçek ve tahmin edilen çıkışlar arasındaki hatadır. $N$ ise eğitim veri kümesindeki veri sayısını göstermektedir.

$$
M S E=\frac{1}{2 N} \sum_{i=1}^{N} h_{i}^{2}
$$

Önerilen ağın eğitimi, hem GY hem de sezgisel algoritmalar olan PSO ve KSA yöntemleri ile gerçekleştirilmiştir. Ağa eğitim verisi olarak gerçek ölçüm değerleri yapılan akım ve gerilim değerleri her bir ay için gün sayısı kadar verilmiştir. Çıkışta ise ağın her bir algoritma için ayrı ayrı hesaplamış olduğu güç değerleri elde edilmektedir. Son aşamada ölçümü yapılan gerçek güç değerleri, ağın hesapladığı güç değerleri karşılaştııılarak ağın performansı belirlenmektedir. Şekil 6'da de görüleceği gibi kullanılan 5 düğümlü (N1 N5) YSA modelini eğitmek üzere her üç algoritma da 9 farklı ağılık değerinin(w1-w9) hesaplanması sağlanmaktadır. Giriş 
katmanında bulunan Akım ve Gerilim değerlerine her ay için hesaplanan ortalama değerler sunulmaktadır. Çıkış katmanında ise ilgili ay için algoritmalar tarafindan tahmin edilen güç değerleri elde edilmektedir.

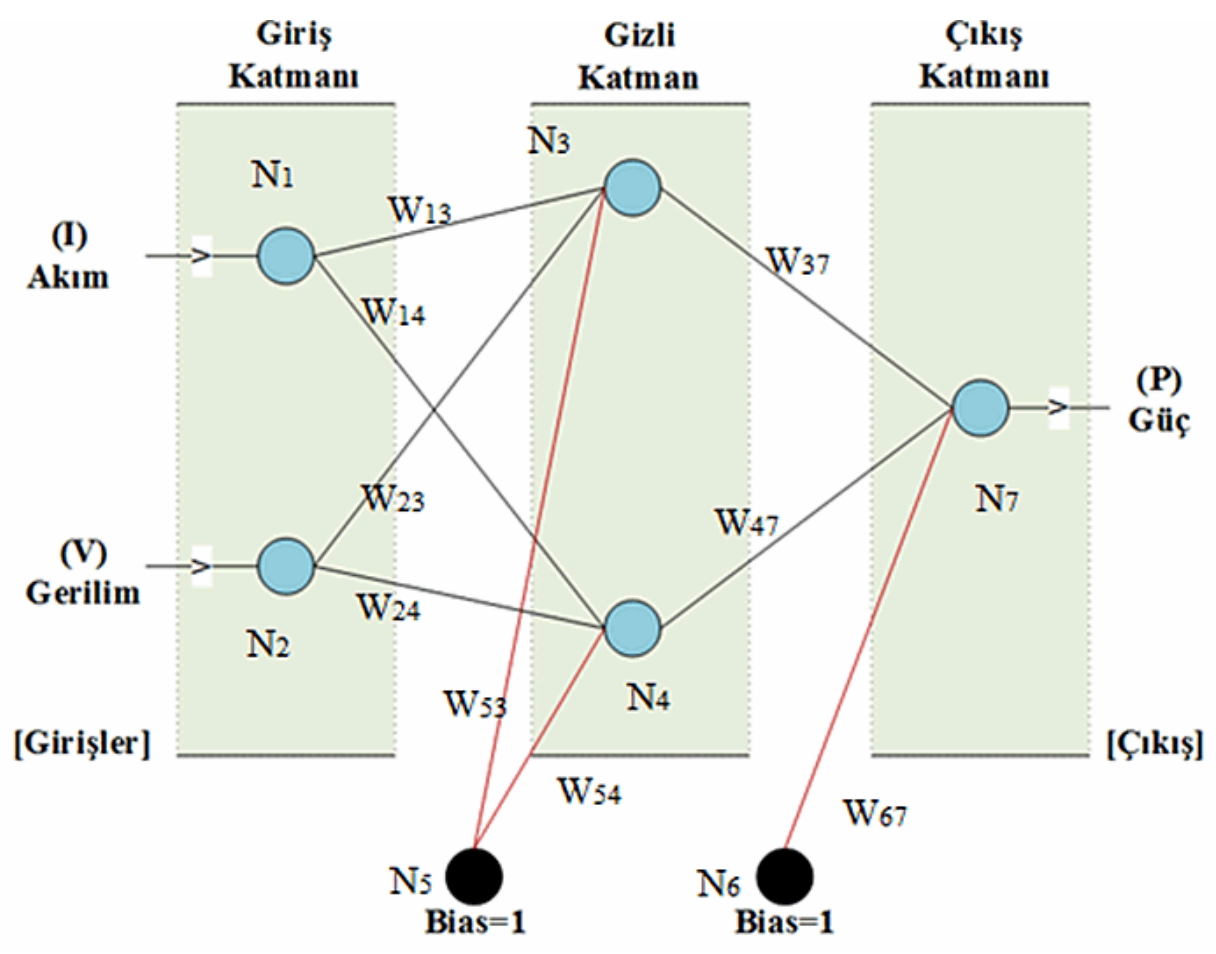

Şekil 6.Yapay Sinir Ağı hücre, bias, ağırlık ve çıkışları

\subsubsection{Geriye Yayılım Algoritması Tabanlı YSA}

Geriye yayılım algoritması çok katmanlı YSA yapıları için düzenli olarak kullanılan bir algoritmadır [18]. Bu algoritmanın öğrenme kuralı, çıkıştaki toplam hatanın en küçük düzeyde hesaplanması ile ağın ağırlıkları için en uygun değerlere ulaşmayı hedefler. Bu çalışmada, FV panel güç çıkışlarının kestirilmesi ve elde edilen sonuçların sezgisel algoritmalarla bulunan sonuçlarla karşılaştırılması amaçlarıyla geriye yayılım algoritmasından yararlanılmışıı. Ağa verilen girdilere karşılık, ağın çıktısı hesaplanır. Beklenen çıktı değeri ile hesaplanan çıktı değerleri karşılaştırılarak çıkan hata geriye doğru ilgili bileşenler üzerine dağıtılır. Sonraki iterasyonda hatanın azaltılması sağlanır. "Hata=Beklenen - Çıktı" olacak şekilde hesaplanır. Mevcut ağ yapısında öncelikle çıkıs katmanı ile ara katman arasındaki ağırlıklar güncellenir. Daha sonra ara katmanlar arası çıkışlar ve en sonunda giriş katmanı ile gizli katman arasındaki ağırlıklar güncellenir. Tablo 1'de GY algoritması sözde kodlarla ifade edilmiştir.

Tablo 1. Geriye yayılım algoritmasının sözde kodlarla ifadesi

\begin{tabular}{|c|c|}
\hline 1: & Ĕ̌itimi Örüntüsü belirlenir \\
\hline 2: & Yapay Sinir Ă̆ı modeli oluşturulur: \\
\hline & $\begin{array}{l}\text { Nöron sayısı, Gizli Katman Nöronları, Çıkış Nöronları } \\
\text { Öğrenme oranı } \eta \text { ve momentum oranı a belirlenir }\end{array}$ \\
\hline 3: & $\begin{array}{l}\text { Rastgele Bağlantı ă̆ırlıkları (Wi) ve bias ağırlıkları } \theta_{1} \text { ve } \theta_{2} \text { belirlenir } \\
\text { Minimum hata değeri belirlenir Emin }\end{array}$ \\
\hline 4: & $\begin{array}{l}\text { Her defasında } 1 \text { set girdi örüntüsü uygulayarak katmanlar arasına yayllır ve } \\
\text { hata hesaplanır }\end{array}$ \\
\hline & Hata $<$ Emin Kontrolü Yapılır \\
\hline 5: & $\begin{array}{l}\text { Çıkışta elde edilen hata gizli katman ve giriş katman yönünde geriye yayılır } \\
\text { ve ağırlıklar güncellenir. }\end{array}$ \\
\hline 6: & 4 'ten 5 'e adımlar şart sağlanıncaya kadar tekrarlanır \\
\hline
\end{tabular}

Şekil 6'daki ağ üzerindeki N 3 düğümünün çıkış değeri Eşitlik 2 ve Eşitlik 3 kullanılarak hesaplanır.

$\mathrm{N}_{3 \text { net }}=\mathrm{N}_{1} * \mathrm{~W}_{13}+\mathrm{N}_{2} * \mathrm{~W}_{23}+$ Bias $* \mathrm{~W}_{53}$ 
$O u t_{N 3}=\frac{1}{1+e-^{{ }^{N 3 n e t}}}$

Modellenen ağ üzerindeki $\mathrm{N}_{4}$ düğümünün çıkış değeri Eşitlik 4 ve Eşitlik 5 kullanılarak hesaplanır. $\mathrm{N}_{5}$ düğümünün çıkış değeri ise Eşitlik 6 ve Eşitlik 7 kullanılarak hesaplanır.

$\mathrm{N}_{4 \text { net }}=\mathrm{N}_{1} * \mathrm{~W}_{14}+\mathrm{N}_{2} * \mathrm{~W}_{24}+$ Bias $* \mathrm{~W}_{54}$

$O u t_{N 3}=\frac{1}{1+e-^{\mathrm{N} \text { net }}}$

N5net $=O u t_{N 3} * W_{37}+O u t_{N 4} * W_{47}+$ Bias $* W_{67}$

$O u t_{N 5}=\frac{1}{1+e-^{\text {N5net }}}$

Eşitlik 7'de hesaplanan Out N $_{\text {5 }}$ ıkış değeri GY algoritması tarafından hesaplanan güç değerini göstermektedir. Bu aşamadan sonra bu değer ile güneş panelinden ölçülen gerçek güç değerinin arasındaki hata hesaplanacak ve geriye yayılım işletilecektir. İleri hesaplama yapıldıktan sonra çıkışta oluşan hatanın katmanlardaki her bir düğüme yayılması sağlanarak ağın ağırlıklarının güncellenmesi gerekmektedir. Geri hesaplama yapılırken aktivasyon fonksiyonunun (Levenberg-Marquardt) çıkışına ilgili girdinin ne kadar etki etki ettiğini bulmak için girdiye göre türev işlemi uygulanır. İleri sürümlü YSA'larda kullanılan $w$ ağırlıkları her seferinde Eşitlik 8'e göre güncellenerek yenilenir. Bu durumda geriye yayılım algoritmasının en önemli noktası $\Delta w$ değerini hesaplayarak en uygun ağırlığa ulaşmaktır. Gerçekte hesaplanan güneş panel güç verileri $g$ ile, $w$ ağırlıklarıyla elde edilen değer y ile gösterilirse, en küçük kareler yöntemiyle elde edilecek hata fonksiyonu $E_{r}$ Eşitlik 9'daki gibi hesaplanır. e ilgili ileri hesaplamadaki ağın hatasını göstermektedir. Eğim düşümü (gradient) olarakta bilinen bu yöntemde, Eşitlik 10'da görüldüğü gibi w'ye göre kısmi türevin gösterdiği yönün tersi zamanla minimuma varacaktır. Burada ๆ katsayısı 0-1 aralığında öğrenme katsayısını göstermektedir.

$w_{13}{ }^{\text {yeni }}=w_{13}{ }^{e s k i}+\Delta w_{13}$

$E_{r}=\frac{1}{2} e^{2}=\frac{1}{2}(g-y)^{2}$

$\Delta \mathrm{w}=-\eta \frac{\partial E_{r}}{\partial w}$

Ağın durdurma kriteri sağlanıncaya kadar belli bir adım sayısınca ağın tüm ağırlıkları Eşitlik 8, 9 ve 10’a göre sürekli olarak güncellenerek, çıkıştaki hata minimuma ulaştırılmaya çalışır. Durdurma kriteri sağlandığında $(<0.001)$, son ağırlıklar ağın ağırlıkları olarak alınır ve ilgili giriş değerlerine göre, çıkıştaki güç değerleri hesaplanır.

\subsubsection{Parçacık Sürü Optimizasyon Algoritması Tabanlı YSA}

Bu çalışmada, FV panel güç çıkışlarının tahmin edilmesi için kullanılan YSA modelinin eğitilmesi için kullanılan sezgisel tekniklerden birisi PSO algoritmasıdır. PSO bir sürü zekası alanı algoritması olup işlemsel zekanın bir alt alanıdır [19]. Bu algoritma popülasyon tabanlı sezgisel bir yöntemdir ve kuş, balık gibi bazı hayvanların yiyecek arama sırasında sergiledikleri davranışlardan esinlenmektedir. PSO algoritmasının amacı, çok boyutlu bir düzlemde tüm parçacıklar için en uygun konumların belirlenmesidir. Algoritma başlangıçta rastgele parçacıklarla başlatılır ve sonra parçacıkların hız ve pozisyonlarının güncellenmesi ile en uygun çözüm aranır. Parçacıklar her nesilde Pbest ve Gbest olarak bilinen iki özel parçacığa göre güncellenir [20]. PSO algoritmasının sözde kodları aşă̆ıdaki Tablo 2' de gösterilmiştir.

Eşitlik 11' de görüldüğü gibi, bir parçacığın hızı her bir iterasyonda aşağıdaki ifade edile güncellenir. Burada, $v_{i}(t+1)$ i. parçacık için yeni hız, c1 ve c2 sırasıyla Pbest ve Gbest için ağırlıklandırma katsayılarıdır. $\mathrm{p}_{\mathrm{i}}(\mathrm{t})$ ve $\mathrm{p}_{\mathrm{i}}(\mathrm{t}+1)$ ise bir $t$ anında sırasıyla $i$. parçacığın pozisyonu ve yeni pozisyonudur. Bu eşitlikteki rand () fonksiyonu da 0 ve 1 arasında düzenli olarak rastgele değer üretir. Bir parçacığın pozisyonu ise Eşitlik 12'ye göre güncellenir.

$v_{i}(t+1)=v_{i}(t)+c_{1} \times$ rand ()$\times\left(\right.$ Pbest $\left._{i}-p_{i}(t)\right)+c_{2} \times$ rand ()$\times\left(\right.$ Gbest $\left.-p_{i}(t)\right)$

$p_{i}(t+1)=p_{i}(t)+v_{i}(t+1)$ 
Tablo 2. PSO algoritmasının sözde kodlarla ifadesi

\begin{tabular}{|c|c|}
\hline 1: & $P$ parçacıklarını rastgele başlat \\
\hline 2: & $P$ içerisinden $P$ best ${ }^{\prime} \mathrm{i}$ belirle \\
\hline 3: & $P$ içerisinden Gbest' i belirle \\
\hline 4: & for (durdurma kriteri sağlanıncaya kadar) \\
\hline 5: & while ( $i=1: P$ 'deki parçacık sayısı) \\
\hline 6: & If $\left(\right.$ Pbest $_{i}$ Pbest'ten daha iyi ise $)$ \\
\hline 7: & Pbest $=$ Pbest $_{i}$ \\
\hline 8: & end if \\
\hline 9: & If (Pbest Gbest'ten daha iyi ise) \\
\hline 10: & Gbest $=$ Pbest \\
\hline 11: & end if \\
\hline 12: & end while \\
\hline 13: & while ( $i=1: P$ 'deki parçacık sayısı) \\
\hline 14: & Velocity ${ }_{i}$ hızları güncelle \\
\hline 15: & Position $_{i}$ pozisyonları güncelle \\
\hline 16: & end while \\
\hline 17: & end for \\
\hline
\end{tabular}

\subsubsection{Klonal Seçim Algoritması Tabanlı YSA}

Klonal seçim prensibi, bağışıklık sisteminin bir antijenik uyarıma karşı bağışıklık cevabının temel özelliklerini tanımlamak amacıyla kullanılan bir yapay bağışıklık optimizasyon algoritmasıdır [21]. Bu prensibe göre sadece antijenleri tanıyan hücrelerin çoğaldığı görülmektedir. Seçilen hücreler afinite benzerlik olgunlaşması işlemine maruz kalırlar. Bu işlem ile seçilmiş olan hücrelerin antijenlere benzerliği geliştirilmiş olur [22]. Şekil 7' de klonal seçim algoritmasının akışşeması ve işlem adımları gösterilmiştir.

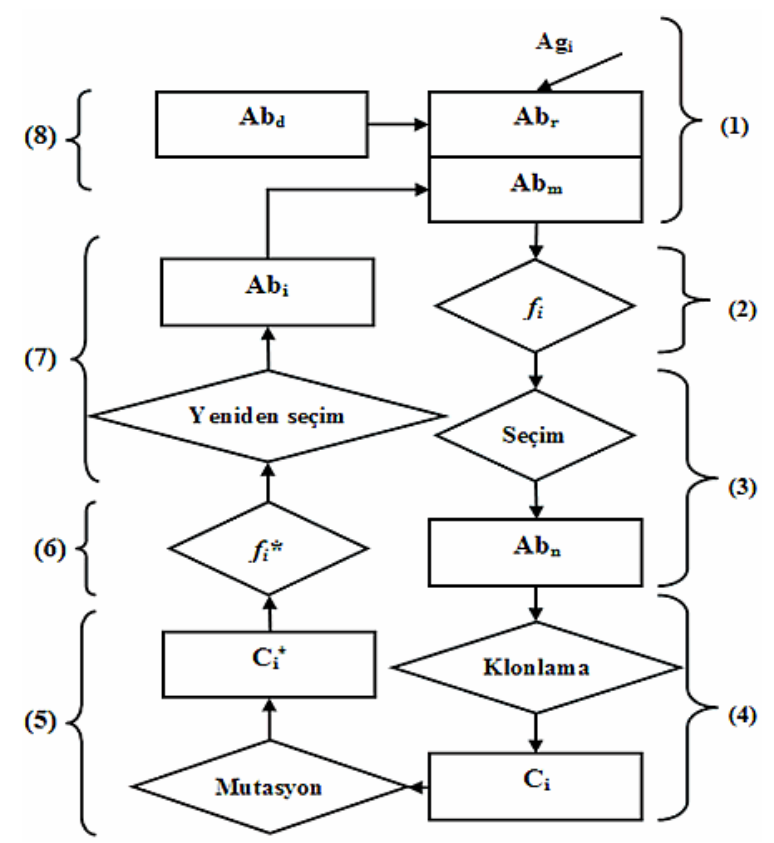

Sekil 7. YBS klonal seçim algoritması akış diyagramı

Klonal seçim algoritmasının işlem adımları şu şekilde açıklanabilir. $A g$ antijen kümesini ve $A b$ antikor kümesini göstermek üzere;

1. Rastgele bir antijen (uyarıcı) kümesi $\left(A_{g i}\right)$ oluşturulur ve tamamı antikor (bağışıklık sistemi için koruma hücre) kümesinde $\left(A_{b}\right)$ temsil edilir. Burada $A_{b}=$ hafıza hücreleri $\left(A_{b m}\right)+$ geriye kalan hücreler $\left(A_{b r}\right)=A_{g}$ olduğu görülebilir.

2. $A_{b}$ kümesindeki $N$ tane $A_{b}^{\prime}$ nin tamamının $A_{g}$ kümesi ile aradaki afinite(benzerlik-uygunluk) ölçümüne göre hesaplanan uygunluk değerlerinin matrisi $\left(f_{i}\right)$ belirlenir.

3. $A_{b}$ kümesinden $n$ tane en yüksek afiniteye sahip $A_{b}$ ' nin seçilmesi ve $A_{b n}$ kümesinin oluşturulması sağlanır.

4. Seçilen $n$ tane $A_{b}$ antijenik uygunluklarına göre bağımsız olarak klonlanırlar (yeniden üretilirler) ve klonlanmış hücrelerin bulunduğu küme $\left(C_{i}\right)$ oluşturulur. En yüksek antijenik uygunluğa sahip olan hücre daha fazla klonlanır. Klonlama için Eşitlik 
13 kullanılır. Bu eşitlikte $N_{c}$ her bir antijen için toplam klonlanma sayısını, $\beta$ klonlama faktörünü ve $N$ toplam antikor sayısını göstermektedir (Klonlama faktörü ile antikor sayısına ait çarpımın tam sayı olmaması durumunda klonlanacak antikor sayısını belirlemek için round/yuvarlama fonksiyonu kullanılmıştır).

$$
N_{c}=\sum_{i=1}^{N} \operatorname{round}(\beta . N)
$$

5. Klonlanmış $C_{i}$ kümesindeki hücreler antijenik uygunluklarına göre ters orantılı olarak mutasyon işlemine tabii tutulurlar ve mutasyona uğramış hücrelerin bulunduğu kümeyi $\left(C_{i}^{*}\right)$ oluştururlar. En yüksek uygunluğa sahip hücre, en küçük mutasyon oranına sahiptir. Böylece en az değişikliğe uğrayan hücre bu hücredir. Her bir hücre Eşitlik 14'teki ifadeye göre mutasyona uğrar. Bu ifadede $\alpha$ mutasyon oranı, $\rho$ mutasyon faktörü ve $f$ ise afinite ölçümleridir (eşitlikte yer alan exp doğal logaritma sayısını ifade eder)

$$
\alpha=\exp (-\rho . f)
$$

6. $\quad C_{i} *$ klonlanmış hücrelerin kümesindeki her bir hücrenin $A_{g}$ antijen kümesindeki hücrelerle ilişkili olarak afinite değerleri $\left(f_{i}^{*}\right)$ hesaplanir.

7. Olgunlaşmış $C_{i}^{*}$ kümesinden en yüksek uygunluğa sahip $A_{b}$ yeniden seçilir. Eğer bu hücrenin uygunluğu $A_{b}$ hafiza hücre kümesindeki aynı sıradaki hücreden daha iyiyse yer değiştirilir.

Son olarak, $A_{b r}$ den $d$ tane en düşük uygunluğa sahip hücre $A_{b d}$ kümesindeki $d$ tane yeni hücre ile değiştirilir ve çeşitlilik sağlanmış olur.

\section{Araştırma Sonuçları ve Tartışma}

Önerilen çalışma üzerindeki tüm deneyler YSA tahmin modeli üzerinde yürütülmüştür. Ayrıca tüm işlemler ve yazılımlar i7 işlemcili, 16 GB RAM belleğe sahip Windows 10 işletim sistemine sahip bir kişisel bilgisayarda MATLAB programı üzerinde gerçekleştirilmiştir.

\subsection{Parametre Seçimleri}

Çalışmada kullanılan çok katmanlı YSA yapısında toplam 9 adet ağılık değerinin GY, PSO ve KSA algoritmaları ile belirlenmesi sağlanmışır. Ağın eğitimi sırasında ilk ağırlık değerleri rastgele belirlenir. Katmanlar arasındaki bu ağıllıklar her bir algoritmanın yapısına göre minimum hata ile son değerlerine ulaştırılır. Ağın çıkış güç değerlerinin kestirilmesi esnasında her bir algoritma 30 defa çalıştıılarak, her bir çalıştırmada elde edilen sonuçların ortalaması alınarak, son FV panel güç çıkış değerleri elde edilmiştir. PSO algoritmasında parçacık sayısı, maksimum nesil sayısı sırasıyla 30 ve 200 olarak; c1 ve c2 sabit katsayıları ise 2.0 olarak ayarlanmıştır. Klonal seçim algoritmasında maksimum nesil sayısı, antikor sayısı, klonlama faktörü ve mutasyon faktörü sirasıyla 200, 30, 0.1 ve 0.5 olarak belirlenmiştir. Her bir algoritmada epok sayısı 200 olarak belirlenmiştir.

\section{2. Ölçüm Doğrulama Kriterleri}

Ölçüm sonuçlarının doğruluğunu değerlendirmek için kullanılan üç popüler kriter Ortalama Mutlak Yüzde Hata(MAPE), Ortalama Karesel Hataların Karekökü(RMSE) ve Varyans ( $\left.\mathrm{R}^{2}\right)^{\prime}$ dir. Bu üç istatiksel kriter Eşitlik (15), Eşitlik (16) ve Eşitlik (17)' de gösterilmiştir. Bu kriterler önerilen YSA modeli üzerinde her bir algoritma kullanılarak tahmin edilen güç değerleri ile ölçümü yapılan gerçek güç değerleri arasındaki ilişkiyi gösterir.

$$
\begin{aligned}
& R M S E=\sqrt{\frac{\sum_{i=1}^{n}\left(F_{\left.i(\text { tahmin edilen })-F_{i(\text { gerçek })}\right)^{2}}^{n}\right.}{n}} \\
& M A P E=\frac{\sum_{i=1}^{n}\left|F_{i(\text { tahmin edilen })}-F_{i(\text { gerçek })}\right|}{n} \\
& R^{2}=1-\left(\frac{\sum_{i=1}^{n}\left|F_{i(\text { tahmin edilen })}-F_{i(\text { gerçek })}\right|^{2}}{\sum_{i=1}^{n}\left(F_{i(\text { gerçek })}\right)^{2}}\right)
\end{aligned}
$$

\subsection{Bulgular}

Bu çalışmada önerilen yöntem ile geriye yayılım algoritması ve iki farklı sezgisel algoritma olan PSO ve KSA yöntemleri yardımıyla eğitilen YSA modelleri kullanılarak güneş panel güç çıkışlarının tahmin edilmesi gerçekleştirilmiştir. Şekil 8(a)' da 2015 Eylül ayında, toplamda 18 gün için $60^{\circ}$ lik panel üzerinde, gerçek güç değerleri ve PSO-YSA hibrit metodu ile elde edilen güç değerlerinin karşılaştııılması yapılmışıtır. Ayrıca bu grafik üzerinde RMSE, MAPE ve $\mathrm{R}^{2}$ ölçüm sonuçları doğrulama kriterleri ile hesaplanan hata değerleri de görülmektedir. Bu hata değerleri sırasıly $0.6874,0.4408$ ve 0.9985 'tir. Şekil 8(b)' de 2015 Mayıs ayında, toplamda 18 gün için $50^{\circ}$ 'lik panel üzerinde, gerçek güç değerleri ve GY-YSA metodu ile elde edilen güç değerlerinin karşılaştırılmıştır. Ayrıca bu grafik üzerinde RMSE, MAPE ve $\mathrm{R}^{2}$ ölçüm sonuçları doğrulama kriterleri ile hesaplanan hata değerleri 
de görülmektedir. Bu hata değerleri sırasıyla 1.0363, 0.4162 ve 0.9966 'dır. Şekil 8(c)' de 2015 Mayıs ayında, toplamda 18 gün için $50^{\circ}$ lik panel üzerinde, gerçek güç değerleri ve KSA-YSA metodu ile elde edilen güç değerlerinin karşılaştırılmasına ilişkin grafikler görülmektedir. Ayrıca bu grafik üzerinde RMSE, MAPE ve $\mathrm{R}^{2}$ ölçüm sonuçları doğrulama kriterleri ile hesaplanan hata değerleri de görülmektedir. Bu hata değerleri sırasıyla $2.5090,1.6141$ ve 0.9805 'tir. Bunun yanında Tablo 3'te ise 2015 Eylül ayında her farklı açıdaki paneller tahmin sonuçları değerlendirildiğinde, PSO-YSA ile elde edilen tahmin sonuçlarının daha başarılı olduğu anlaşılmaktadır.
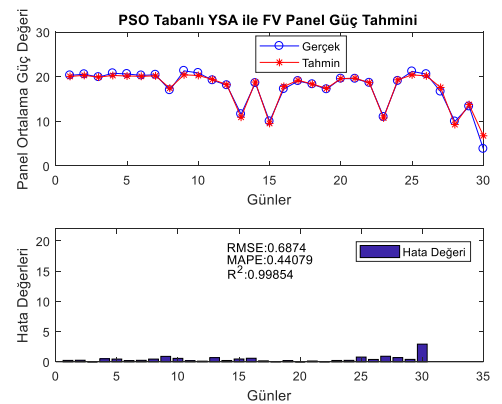

(a)
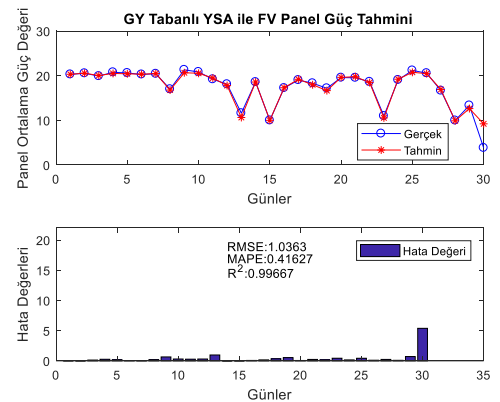

(b)
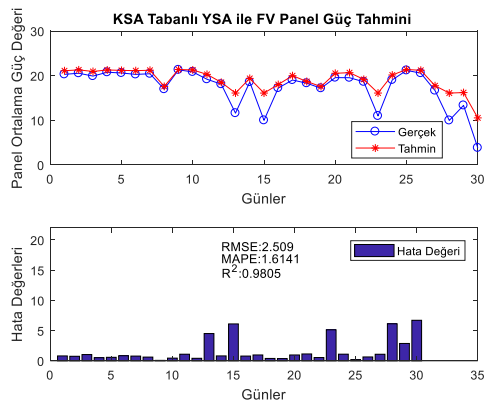

(c)

Sekil 8. 2015 Eylül PV panel güç çıkışlarının tahmin edilmesi

Tablo 3. Eylül 2015 Tüm paneller için elde edilen sonuçların karşılaştırılması.

\begin{tabular}{|c|c|c|c|c|c|c|c|c|c|c|c|c|c|c|c|c|c|c|}
\hline & \multicolumn{3}{|c|}{$10^{\circ}$} & \multicolumn{3}{|c|}{$20^{\circ}$} & \multicolumn{3}{|c|}{$30^{\circ}$} & \multicolumn{3}{|c|}{$40^{\circ}$} & \multicolumn{3}{|c|}{$50^{\circ}$} & \multicolumn{3}{|c|}{$60^{\circ}$} \\
\hline & $\begin{array}{l}4 \\
0 \\
0 \\
0 \\
0\end{array}$ & 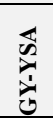 & 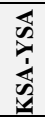 & $\begin{array}{l}\text { यर } \\
\vdots \\
0 \\
0\end{array}$ & 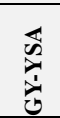 & 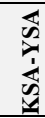 & 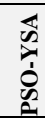 & $\begin{array}{l}\overrightarrow{0} \\
\dot{i} \\
\dot{0}\end{array}$ & 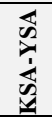 & $\begin{array}{l}\vec{x} \\
\vdots \\
\vdots \\
0\end{array}$ & 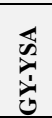 & 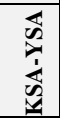 & 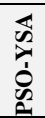 & 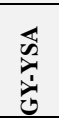 & 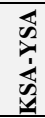 & $\begin{array}{l}\vec{n} \\
0 \\
0 \\
0\end{array}$ & 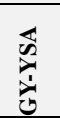 & 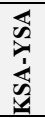 \\
\hline $\begin{array}{l}0 \\
0 \\
2\end{array}$ & $\begin{array}{l}\text { Ra } \\
\stackrel{5}{S}\end{array}$ & 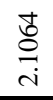 & 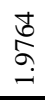 & $\begin{array}{l}\text { ôे } \\
\text { to }\end{array}$ & \&্ট寸 & $\begin{array}{l}\text { त్రి } \\
\stackrel{-}{-}\end{array}$ & $\begin{array}{l}\text { o. } \\
\text { th } \\
\text { the }\end{array}$ & $\begin{array}{l}0 \\
0 \\
\infty \\
0 \\
0\end{array}$ & 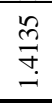 & 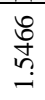 & 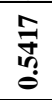 & 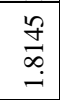 & $\stackrel{\text { In }}{\text { İ }}$ & $\begin{array}{l}\vec{y} \\
\stackrel{y}{d} \\
i\end{array}$ & $\begin{array}{l}\bar{\infty} \\
\stackrel{\rightarrow}{\rightarrow}\end{array}$ & 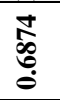 & 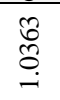 & 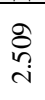 \\
\hline $\begin{array}{ll}x \\
\frac{\pi}{2} \\
\frac{1}{2}\end{array}$ & 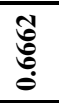 & $\begin{array}{l}\hat{\alpha} \\
\stackrel{0}{0} \\
0\end{array}$ & 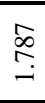 & 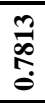 & $\begin{array}{l}0 \\
0 \\
0 \\
0 \\
0 \\
0\end{array}$ & 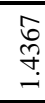 & 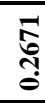 & 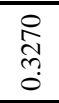 & $\begin{array}{l}\text { Oे. } \\
\text { O. }\end{array}$ & \begin{tabular}{l} 
â \\
\multirow{0}{0}{}
\end{tabular} & 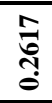 & $\begin{array}{l}\vec{\infty} \\
\infty \\
\stackrel{0}{\longrightarrow}\end{array}$ & 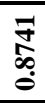 & 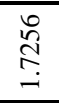 & $\begin{array}{l}\text { \& } \\
\vdots \\
0\end{array}$ & $\begin{array}{l}\infty \\
\stackrel{8}{+} \\
\stackrel{9}{0}\end{array}$ & $\begin{array}{l}0 \\
\dot{\beta} \\
0 \\
0\end{array}$ & 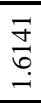 \\
\hline$\approx$ & $\begin{array}{l}\text { L } \\
\text { âे }\end{array}$ & $\begin{array}{l}0 \\
0 \\
\infty \\
0 \\
0\end{array}$ & $\begin{array}{l}\text { o. } \\
\text { ò } \\
\text { o. }\end{array}$ & 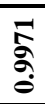 & $\begin{array}{l}\text { J } \\
\text { So } \\
0\end{array}$ & 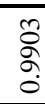 & $\begin{array}{l}\text { के } \\
\text { ลे } \\
\text { s. }\end{array}$ & $\begin{array}{l}0 \\
\text { o. } \\
\text { o. }\end{array}$ & $\begin{array}{l}\text { fa } \\
\text { ò }\end{array}$ & $\begin{array}{l}\text { tै } \\
\text { Oे }\end{array}$ & $\begin{array}{l}\text { mo } \\
\text { o. }\end{array}$ & $\begin{array}{l}\bar{a} \\
\bar{a} \\
0\end{array}$ & $\begin{array}{l}\text { 공 } \\
\text { a }\end{array}$ & $\begin{array}{l}\hat{\mathbf{a}} \\
\hat{0}\end{array}$ & $\begin{array}{l}\text { ta } \\
\text { هे } \\
\text { oे }\end{array}$ & $\begin{array}{l}\text { की } \\
\text { ồ } \\
0\end{array}$ & $\begin{array}{l}\hat{\circ} \\
\text { ò } \\
0\end{array}$ & 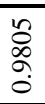 \\
\hline
\end{tabular}

Şekil 9(a)' da 2015 Ekim ayında 40'lik panel üzerinde, gerçek güç değerleri ve PSO-YSA metodu ile elde edilen güç değerlerinin karşılaştırılmasına ilişkin grafikler görülmektedir. Şekil 9(b)' de 2015 Ekim ayında $10^{\circ}$ 'lik panel üzerinde, gerçek güç değerleri ve GY-YSA metodu ile elde edilen güç değerleri, Şekil 9(c)' da ise 2015 Ekim ayında $10^{\circ}$ 'lik panel üzerinde, gerçek güç değerleri ve KSA-YSA metodu ile elde edilen güç değerleri sunulmuştur. Bu grafiksel sonuçlar RMSE, MAPE ve $\mathrm{R}^{2}$ ölçüm sonuçları doğrulama kriterleri bakımından değerlendirildiğinde, PSO-YSA ile elde edilen tahmin sonuçlarının GY-YSA ve KSA-YSA sonuçlarına göre daha başarılı olduğu anlaşılmaktadır.
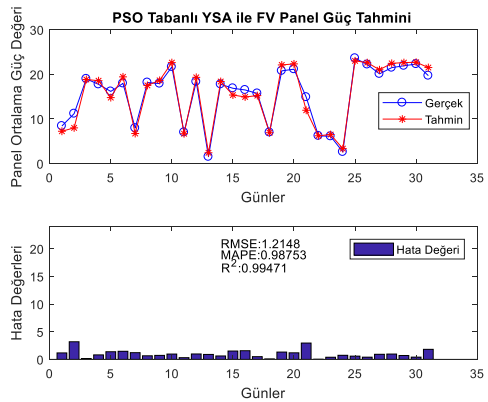

(a)
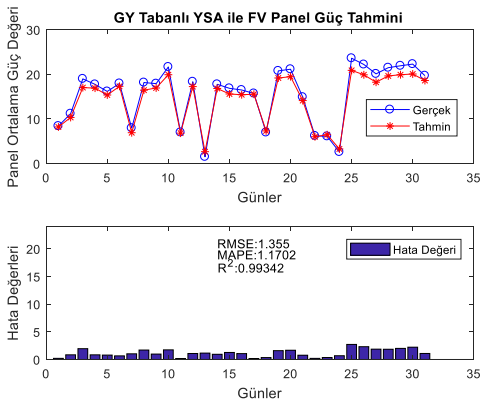

(b)
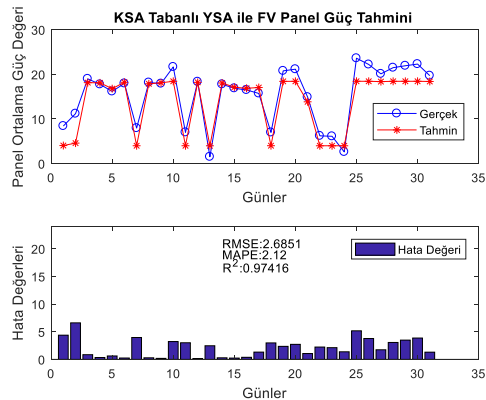

(c)

Sekil 9. 2015 Ekim PV panel güç çıkışlarının tahmin edilmesi

Bunun yanında Tablo 4'te ise 2015 Ekim ayında her farklı açıdaki paneller için PSO-YSA, GY-YSA ve KSA-YSA tahmin sonuçları ayrıntılı olarak tablolanmıştır. Bu tablolardan da görülebileceği gibi PSO-YSA ile elde edilen tahmin sonuçlarının genel olarak diğerlerine göre daha başarılı olduğu görülmektedir. Bazı testlerde ise GY-YSA'nın PSO-YSA sonuçlarına yakın olmakla birlikte daha başarılı olduğu göze çarpmaktadır. 
Tablo 4. Ekim 2015 Tüm paneller için elde edilen sonuçların karşılaştırılması.

\begin{tabular}{|c|c|c|c|c|c|c|c|c|c|c|c|c|c|c|c|c|c|c|}
\hline & \multicolumn{3}{|c|}{$10^{\circ}$} & \multicolumn{3}{|c|}{$20^{\circ}$} & \multicolumn{3}{|c|}{$30^{\circ}$} & \multicolumn{3}{|c|}{$40^{\circ}$} & \multicolumn{3}{|c|}{$50^{\circ}$} & \multicolumn{3}{|c|}{$60^{\circ}$} \\
\hline & $\begin{array}{l}\widehat{T} \\
0 \\
0 \\
0 \\
0\end{array}$ & $\begin{array}{l}\overrightarrow{0} \\
\dot{\lambda} \\
\overrightarrow{0}\end{array}$ & 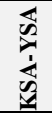 & 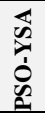 & 岕 & 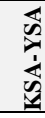 & $\begin{array}{l}\overleftarrow{2} \\
0 \\
0 \\
0\end{array}$ & 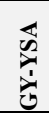 & 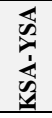 & $\begin{array}{l}\overleftarrow{2} \\
\text { D. } \\
0 \\
0\end{array}$ & 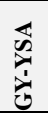 & 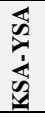 & 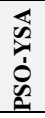 & 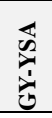 & 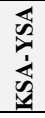 & 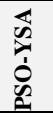 & 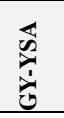 & 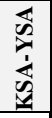 \\
\hline 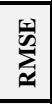 & $\begin{array}{l}\infty \\
\stackrel{\infty}{\infty} \\
\stackrel{2}{2}\end{array}$ & $\begin{array}{l}5 \\
\text { s. } \\
\text { in }\end{array}$ & 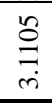 & $\begin{array}{l}\infty \\
\infty \\
o \\
o \\
- \\
\end{array}$ & 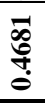 & 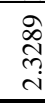 & 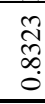 & 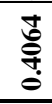 & $\begin{array}{l}\text { iे } \\
\text { ì }\end{array}$ & $\stackrel{\infty}{\stackrel{\infty}{9}}$ & $\stackrel{n}{\stackrel{n}{\sim}}$ & $\begin{array}{l}\vec{\nabla} \\
0 \\
0 \\
i\end{array}$ & 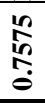 & $\stackrel{8}{\stackrel{0}{0}}$ & $\begin{array}{l}\text { مू } \\
\text { ते } \\
\text { na }\end{array}$ & $\begin{array}{l}\overline{\text { ন }} \\
\text { }\end{array}$ & 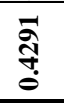 & 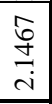 \\
\hline$\frac{n}{\frac{1}{2}}$ & $\begin{array}{c}a \\
\substack{0 \\
\infty \\
0 \\
0}\end{array}$ & $\begin{array}{l}\text { Oొ } \\
\stackrel{0}{0}\end{array}$ & $\begin{array}{l}\text { in } \\
\text { d } \\
i\end{array}$ & $\begin{array}{l}\hat{\delta} \\
\stackrel{0}{0}\end{array}$ & 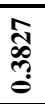 & 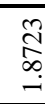 & 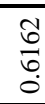 & ڤેे & 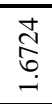 & \begin{tabular}{l}
$\hat{n}$ \\
\multirow{2}{0}{} \\
$\stackrel{0}{0}$
\end{tabular} & $\stackrel{\overbrace{}}{\stackrel{\Xi}{\Xi}}$ & $\stackrel{\vec{i}}{\vec{i}}$ & : & 胥 & 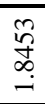 & $\begin{array}{l}\text { ta } \\
\text { के } \\
\text { o. }\end{array}$ & 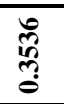 & 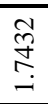 \\
\hline$\approx$ & $\begin{array}{l}\text { वे } \\
\text { वे }\end{array}$ & $\begin{array}{l}\text { बे } \\
\text { aे }\end{array}$ & $\begin{array}{l}0 \\
0 \\
0 \\
0\end{array}$ & $\begin{array}{l}\text { ô } \\
\text { } \\
0\end{array}$ & ڤू. & $\begin{array}{l}\overline{\vec{j}} \\
\stackrel{0}{0} \\
\stackrel{0}{0}\end{array}$ & 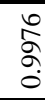 & 大. & 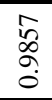 & 商 & $\begin{array}{l}\text { 苑 } \\
\text { o. }\end{array}$ & $\begin{array}{l}\text { I } \\
\text { I } \\
\text { o }\end{array}$ & $\begin{array}{l}\hat{a} \\
\hat{a} \\
\text { a }\end{array}$ & 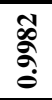 & 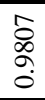 & बे & $\begin{array}{l}\text { to } \\
\text { aे }\end{array}$ & 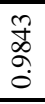 \\
\hline
\end{tabular}

Tablo 5. Mayıs 2015 Tüm paneller için elde edilen sonuçların karşılaştırılması.

\begin{tabular}{|c|c|c|c|c|c|c|c|c|c|c|c|c|c|c|c|c|c|c|}
\hline & \multicolumn{3}{|c|}{$10^{\circ}$} & \multicolumn{3}{|c|}{$20^{\circ}$} & \multicolumn{3}{|c|}{$30^{\circ}$} & \multicolumn{3}{|c|}{$40^{\circ}$} & \multicolumn{3}{|c|}{$50^{\circ}$} & \multicolumn{3}{|c|}{$60^{\circ}$} \\
\hline & 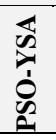 & 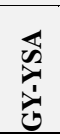 & 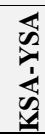 & 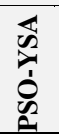 & $\begin{array}{l}\text { क्र } \\
\text { तो } \\
\end{array}$ & 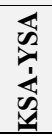 & \begin{tabular}{l}
1 \\
0 \\
0 \\
0 \\
0 \\
\multirow{2}{0}{}
\end{tabular} & 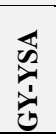 & 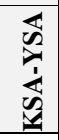 & 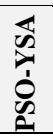 & 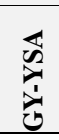 & 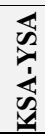 & 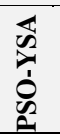 & 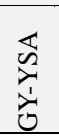 & 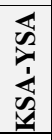 & $\begin{array}{l}\overrightarrow{0} \\
0 \\
0 \\
0 \\
0\end{array}$ & 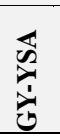 & 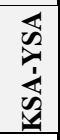 \\
\hline$\sum_{\underline{\pi}}^{5}$ & 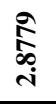 & $\begin{array}{l}\text { â } \\
\text { Oे }\end{array}$ & $\begin{array}{l}\infty \\
\infty \\
\hat{o} \\
\dot{+}\end{array}$ & $\stackrel{\text { Iִ }}{\longrightarrow}$ & $\begin{array}{l}n \\
\tilde{f} \\
\tilde{c} \\
i\end{array}$ & $\begin{array}{l}0 \\
\infty \\
\stackrel{\infty}{\infty} \\
m\end{array}$ & $\begin{array}{l}\mathbb{N} \\
\text { in }\end{array}$ & 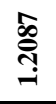 & $\begin{array}{l}\hat{\sigma} \\
\text { i } \\
\text {. }\end{array}$ & $\begin{array}{l}0 \\
\text { f̦̣ } \\
\text { in }\end{array}$ & 今. & $\begin{array}{l}\text { ते } \\
\text { लn }\end{array}$ & 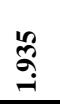 & $\frac{\tilde{\sigma}}{\dot{m}}$ & 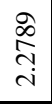 & 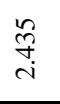 & $\begin{array}{l}\stackrel{+}{\Delta} \\
\stackrel{\infty}{m}\end{array}$ & $\stackrel{\leftrightarrow}{\leftrightarrow}$ \\
\hline$\frac{\pi}{\frac{\pi}{2}}$ & $\begin{array}{l}\infty \\
\stackrel{\infty}{\oplus} \\
\stackrel{\sim}{\sim}\end{array}$ & $\begin{array}{l}\text { ते } \\
\hat{n} \\
\text { on }\end{array}$ & $\begin{array}{l}\text { त̂ } \\
\text { ले }\end{array}$ & $\begin{array}{l}\text { ָ̃ } \\
\stackrel{\Xi}{0}\end{array}$ & 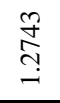 & $\begin{array}{l}\stackrel{\partial}{a} \\
\stackrel{d}{i}\end{array}$ & 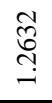 & $\underset{:}{\mathbb{S}}$ & $\begin{array}{l}\stackrel{2}{2} \\
\text { S. }\end{array}$ & 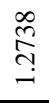 & $\begin{array}{l}\hat{S} \\
\text { S. }\end{array}$ & $\stackrel{\Re}{\stackrel{\leftrightarrow}{i}}$ & 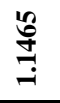 & 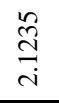 & $\begin{array}{l}\underset{+}{ \pm} \\
\stackrel{f}{-} \\
\end{array}$ & 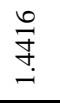 & $\begin{array}{l}\stackrel{\circ}{\circ} \\
\stackrel{\circ}{-}\end{array}$ & $\begin{array}{l}\stackrel{9}{2} \\
\stackrel{2}{3}\end{array}$ \\
\hline$\approx$ & $\begin{array}{l}\text { 总 } \\
\text { Oे }\end{array}$ & $\begin{array}{l}+ \\
\text { a } \\
\text { aे }\end{array}$ & $\begin{array}{l}\text { o. } \\
\text { ò }\end{array}$ & $\begin{array}{l}\text { W } \\
\text { ô }\end{array}$ & $\begin{array}{l}n \\
\infty \\
o \\
0\end{array}$ & $\begin{array}{l}\vec{b} \\
\stackrel{0}{0} \\
0\end{array}$ & $\begin{array}{l}\bar{\alpha} \\
\text { oे }\end{array}$ & $\hat{\sigma}$ & $\begin{array}{l}\tilde{I} \\
0 \\
0 \\
0\end{array}$ & $\begin{array}{l}\bar{b} \\
\stackrel{0}{\circ} \\
\stackrel{0}{0}\end{array}$ & 青 & 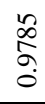 & $\stackrel{n}{a}$ & 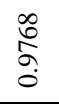 & $\begin{array}{l}0 \\
\infty \\
\stackrel{0}{0} \\
0\end{array}$ & $\begin{array}{l}\hat{\infty} \\
\stackrel{0}{0}\end{array}$ & $\begin{array}{l}\stackrel{n}{\kappa} \\
\hat{\sigma}\end{array}$ & : \\
\hline
\end{tabular}

Tablo 6. Haziran 2015 Tüm paneller için elde edilen sonuçların karş1laştırılması

\begin{tabular}{|c|c|c|c|c|c|c|c|c|c|c|c|c|c|c|c|c|c|c|}
\hline & \multicolumn{3}{|c|}{$10^{\circ}$} & \multicolumn{3}{|c|}{$20^{\circ}$} & \multicolumn{3}{|c|}{$30^{\circ}$} & \multicolumn{3}{|c|}{$40^{\circ}$} & \multicolumn{3}{|c|}{$50^{\circ}$} & \multicolumn{3}{|c|}{$60^{\circ}$} \\
\hline & 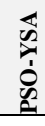 & d. & 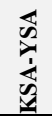 & 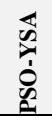 & 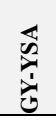 & 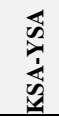 & 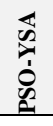 & 䓂 & 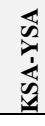 & $\begin{array}{l}\overleftarrow{0} \\
0 \\
0 \\
0 \\
0\end{array}$ & 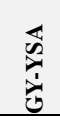 & 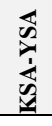 & 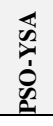 & 䓂 & 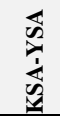 & 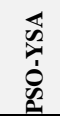 & $\begin{array}{l}\vec{D} \\
\vec{d} \\
\end{array}$ & 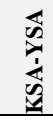 \\
\hline$\sum_{\Perp}^{5}$ & 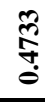 & $\begin{array}{l}\vec{f} \\
\text { 。 } \\
0\end{array}$ & $\overrightarrow{\vec{n}}$ & 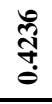 & $\begin{array}{l}\text { Tे } \\
\text { n. } \\
0\end{array}$ & $\begin{array}{l}\widehat{\infty} \\
\infty \\
\stackrel{0}{0} \\
\end{array}$ & $\stackrel{\infty}{\stackrel{0}{0}}$ & $\begin{array}{l}0 \\
5 \\
0 \\
0\end{array}$ & 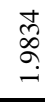 & 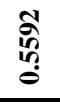 & $\begin{array}{l}\tilde{F} \\
\text { in } \\
\text { on } \\
\end{array}$ & 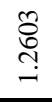 & $\begin{array}{l}\text { ఫ్ర్రి } \\
\stackrel{0}{0}\end{array}$ & 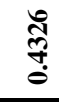 & $\stackrel{\mathbb{Z}}{-}$ & $\begin{array}{l}\frac{7}{0} \\
0 \\
0\end{array}$ & $\begin{array}{l}\bar{\infty} \\
\stackrel{+}{+} \\
\stackrel{0}{0}\end{array}$ & 吕 \\
\hline 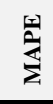 & $\stackrel{5}{0}$ & $\begin{array}{l}n \\
0 \\
0 \\
0 \\
0\end{array}$ & $\begin{array}{l}0 \\
\stackrel{0}{0} \\
\stackrel{0}{-}\end{array}$ & 亭 & $\frac{J}{f}$ & 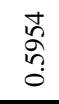 & $\stackrel{\bar{s}}{\mathrm{in}}$ & $\begin{array}{l}0 \\
\infty \\
0 \\
0 \\
\end{array}$ & $\begin{array}{l}\stackrel{0}{1} \\
\stackrel{2}{-}\end{array}$ & 点 & $\begin{array}{l}\infty \\
\stackrel{+}{0} \\
\stackrel{3}{0}\end{array}$ & $\begin{array}{l}\stackrel{a}{\hat{~}} \\
\hat{0}\end{array}$ & 点 & ț & $\begin{array}{l}\infty \\
\stackrel{\infty}{6} \\
\stackrel{-}{*}\end{array}$ & $\begin{array}{l}\infty \\
0 \\
0 \\
0 \\
0\end{array}$ & 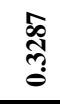 & $\underset{\stackrel{f}{\sim}}{\stackrel{F}{-}}$ \\
\hline$\approx$ & 亏ั & $\begin{array}{l}\hat{\alpha} \\
\text { ò }\end{array}$ & $\begin{array}{l}\otimes \\
\& \\
\stackrel{0}{0}\end{array}$ & مै & مू. & $\begin{array}{l}+ \\
\text { o. } \\
\text { oे }\end{array}$ & $\begin{array}{l}\text { oे } \\
\text { â }\end{array}$ & $\begin{array}{l}\text { \& } \\
\text { Sิ }\end{array}$ & $\begin{array}{l}\text { \% } \\
\stackrel{0}{0}\end{array}$ & बू. & Sू & $\begin{array}{l}\stackrel{\circ}{\circ} \\
\stackrel{\alpha}{0}\end{array}$ & 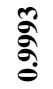 & ڤ̆ & $\begin{array}{l}\tilde{n} \\
\hat{\sigma} \\
\sigma\end{array}$ & 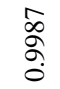 & 亏ू. & gे \\
\hline
\end{tabular}

Tablo 7. Temmuz 2015 Tüm paneller için elde edilen sonuçların karşılaştırılması.

\begin{tabular}{|c|c|c|c|c|c|c|c|c|c|c|c|c|c|c|c|c|c|c|}
\hline & \multicolumn{3}{|c|}{$10^{\circ}$} & \multicolumn{3}{|c|}{$20^{\circ}$} & \multicolumn{3}{|c|}{$30^{\circ}$} & \multicolumn{3}{|c|}{$40^{\circ}$} & \multicolumn{3}{|c|}{$50^{\circ}$} & \multicolumn{3}{|c|}{$60^{\circ}$} \\
\hline & \begin{tabular}{l}
\multicolumn{1}{c}{} \\
0 \\
0 \\
0 \\
0 \\
0
\end{tabular} & 䓂 & 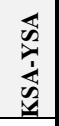 & $\begin{array}{l}\overleftrightarrow{1} \\
0 \\
0 \\
0 \\
0\end{array}$ & 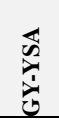 & 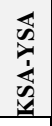 & 苑 & & 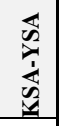 & 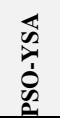 & $\begin{array}{l}\overleftrightarrow{\pi} \\
\vdots \\
\vdots \\
0\end{array}$ & 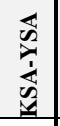 & $\begin{array}{l}\overrightarrow{0} \\
0 \\
0 \\
0 \\
0\end{array}$ & 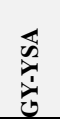 & 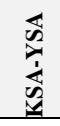 & $\begin{array}{l}\overrightarrow{1} \\
0 \\
0 \\
0 \\
0 \\
0\end{array}$ & 䓂 & 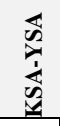 \\
\hline$\sum_{\pi}^{5}$ & 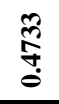 & $\begin{array}{l}\text { fo } \\
\stackrel{0}{0} \\
0\end{array}$ & $\overrightarrow{\vec{n}}$ & 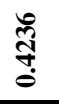 & 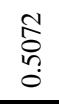 & $\begin{array}{l}\infty \\
\infty\end{array}$ & 趈 & \begin{tabular}{l}
0 \\
\multirow{5}{0}{} \\
0 \\
\end{tabular} & $\begin{array}{l}\stackrel{+}{0} \\
\stackrel{2}{-} \\
\stackrel{-}{-}\end{array}$ & 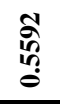 & $\begin{array}{l}\sqrt{n} \\
\text { in } \\
0 \\
0\end{array}$ & 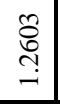 & స్ర్రి & 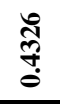 & $\stackrel{\text { त̇ }}{=}$ & $\begin{array}{l}\frac{J}{8} \\
\stackrel{0}{0} \\
\dot{0}\end{array}$ & $\begin{array}{l}\overline{8} \\
\stackrel{+}{+}+ \\
\end{array}$ & 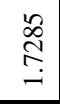 \\
\hline 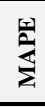 & ֻ. & $\begin{array}{l}\text { م. } \\
\text { م. } \\
0\end{array}$ & $\begin{array}{l}0 \\
\stackrel{0}{0} \\
\stackrel{0}{0} \\
-\end{array}$ & 㝘 & $\underset{f}{\frac{f}{8}}$ & 0 & & 0 & 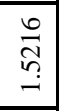 & 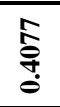 & 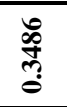 & \begin{tabular}{l|l}
\multirow{2}{*}{} \\
$\stackrel{9}{0}$ \\
0
\end{tabular} & 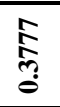 & 鸪 & $\begin{array}{l}\tilde{\infty} \\
\tilde{\delta} \\
\stackrel{-}{-}\end{array}$ & $\begin{array}{l}0 \\
0 \\
0 \\
0 \\
0\end{array}$ & 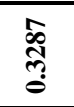 & $\underset{\stackrel{J}{J}}{\bar{J}}$ \\
\hline$\approx$ & Sू̆ & बू. & $\begin{array}{l}0 \\
\& \\
\stackrel{0}{0}\end{array}$ & 参 & $\begin{array}{l}\text { ळ. } \\
\text { ò }\end{array}$ & 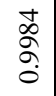 & $\hat{\not g}$ & 0 & $\begin{array}{l}\stackrel{0}{\circ} \\
\stackrel{\circ}{0}\end{array}$ & बू. & 参 & $\begin{array}{l}\circ \\
\swarrow \\
\sigma \\
0\end{array}$ & 气ू. & $\begin{array}{l}\text { तू } \\
\text { gे }\end{array}$ & $\begin{array}{l}\hat{n} \\
\hat{\sigma} \\
0\end{array}$ & $\begin{array}{l}\text { o. } \\
\text { ò } \\
0\end{array}$ & ô & $\stackrel{\partial}{\partial}$ \\
\hline
\end{tabular}

Mayıs 2015 ve Mayıs 2016 ayları arasında, her bir panelden her bir algoritma kullanılarak elde edilen FV panel güç çıkışlarının ölçüm kriterlerine göre ayrıntılı olarak karşılaştırması sırasıyla Tablo 5, Tablo 6, Tablo 7, Tablo 8, Tablo 9, Tablo 10'dasunulmuştur. $\mathrm{Bu}$ ayrıntılı tablolardan da görüldüğü gibi, her ölçüm kriterinde de en iyi sonuçlar genel olarak sezgisel bir yöntem olan PSO algoritması ile eğitim yapılan YSA modelinde elde edilmiş̧ir. Diğer bir sezgisel teknik olan KSA algoritması ile elde edilen sonuçlar 
ise, bazı ayların bazı açılarındaki panellerinde yüksek olsa da genellikle diğer iki algoritmaya göre daha düşüktür. Bazı tahmin sonuçlarında ise GY ile eğitilen YSA yapısının sonuçlarının PSO ile elde edilen doğrulama kriterleri değerlerine yüksek veya yakın olmakla birlikte daha başarılı olduğu görülmektedir.

Tablo 8. Ağustos 2015 Tüm paneller için elde edilen sonuçların karș1laștırılması

\begin{tabular}{|c|c|c|c|c|c|c|c|c|c|c|c|c|c|c|c|c|c|c|}
\hline & \multicolumn{3}{|c|}{$10^{0}$} & \multicolumn{3}{|c|}{$20^{\circ}$} & \multicolumn{3}{|c|}{$30^{\circ}$} & \multicolumn{3}{|c|}{$40^{\circ}$} & \multicolumn{3}{|c|}{$50^{\circ}$} & \multicolumn{3}{|c|}{$60^{\circ}$} \\
\hline & 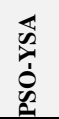 & 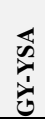 & 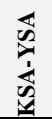 & 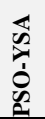 & 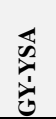 & 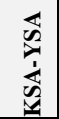 & $\begin{array}{l}\overleftarrow{n} \\
0 \\
0 \\
0 \\
2\end{array}$ & 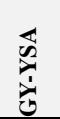 & 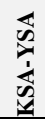 & $\begin{array}{l}\overleftrightarrow{0} \\
0 \\
0 \\
0 \\
0\end{array}$ & 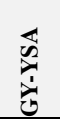 & 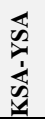 & $\begin{array}{l}\overleftarrow{D} \\
0 \\
0 \\
0 \\
2\end{array}$ & 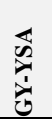 & 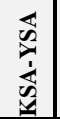 & 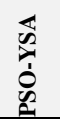 & $\begin{array}{l}\vec{\lambda} \\
\dot{\hat{d}} \\
\end{array}$ & 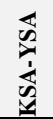 \\
\hline$\frac{\pi}{2}$ & 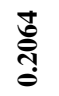 & 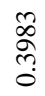 & $\begin{array}{l}\text { ¿े } \\
\stackrel{0}{\circ}\end{array}$ & $\begin{array}{l}\stackrel{\infty}{\pi} \\
\stackrel{m}{0}\end{array}$ & $\begin{array}{l}\infty \\
\stackrel{+}{+} \\
0\end{array}$ & $\begin{array}{l}\infty \\
\infty \\
\infty \\
\infty \\
-1\end{array}$ & 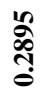 & $\stackrel{\stackrel{\infty}{f}}{\underset{f}{f}}$ & 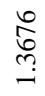 & 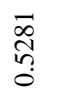 & 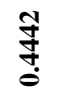 & & 丞 & 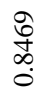 & 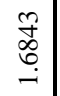 & ثิ & 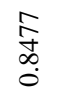 & $\begin{array}{l}\stackrel{0}{W} \\
\stackrel{i}{i}\end{array}$ \\
\hline$\sum_{\approx}^{0}$ & 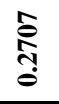 & 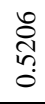 & $\begin{array}{l}\text { مू } \\
\text { aे }\end{array}$ & $\begin{array}{l}\text { 兽 } \\
\stackrel{d}{0}\end{array}$ & $\begin{array}{l}0 \\
0 \\
0 \\
0\end{array}$ & $\begin{array}{l}a \\
0 \\
0 \\
i \\
i\end{array}$ & 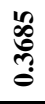 & $\begin{array}{l}\infty \\
\stackrel{\infty}{\infty} \\
\stackrel{-}{+}\end{array}$ & $\begin{array}{l}\tilde{n} \\
\hat{n} \\
i\end{array}$ & $\begin{array}{l}\text { Î } \\
\text { fे } \\
\text { Oे }\end{array}$ & 萢 & 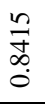 & 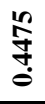 & & $\begin{array}{l}0 \\
\check{S} \\
-\end{array}$ & 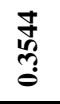 & $\stackrel{\vec{\partial}}{-}$ & $\begin{array}{l}\infty \\
\stackrel{i}{ } \\
i \\
i\end{array}$ \\
\hline$\approx$ & $\begin{array}{l}\infty \\
\text { ă } \\
\text { on }\end{array}$ & $\begin{array}{l}\text { 亏े } \\
\text { oे }\end{array}$ & 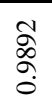 & 今. & ڤ. & $\begin{array}{l}\bar{\delta} \\
\stackrel{0}{0} \\
\stackrel{0}{0}\end{array}$ & S. & $\bar{\sigma}$ & $\begin{array}{l}\widehat{\infty} \\
\stackrel{\infty}{\circ} \\
0\end{array}$ & $\begin{array}{l}\hat{\sigma} \\
\text { aे } \\
\text { of }\end{array}$ & $\begin{array}{l}\text { مै } \\
\text { }\end{array}$ & 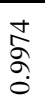 & $\begin{array}{l}\text { Sू } \\
\text { ğ }\end{array}$ & $\begin{array}{l}\text { gै } \\
\text { gे }\end{array}$ & $\begin{array}{l}\stackrel{0}{ } \\
\stackrel{0}{0} \\
\stackrel{0}{0}\end{array}$ & ڤั้ & $\begin{array}{l}0 \\
\delta \\
\delta \\
0\end{array}$ & $\begin{array}{l}\vec{t} \\
\stackrel{\infty}{\circ} \\
\stackrel{0}{0}\end{array}$ \\
\hline
\end{tabular}

Tablo 9. Kasım 2015 Tüm paneller için elde edilen sonuçların karşılaştırılması

\begin{tabular}{|c|c|c|c|c|c|c|c|c|c|c|c|c|c|c|c|c|c|c|}
\hline & \multicolumn{3}{|c|}{$10^{\circ}$} & \multicolumn{3}{|c|}{$20^{\circ}$} & \multicolumn{3}{|c|}{$30^{\circ}$} & \multicolumn{3}{|c|}{$40^{\circ}$} & \multicolumn{3}{|c|}{$50^{\circ}$} & \multicolumn{3}{|c|}{$60^{\circ}$} \\
\hline & 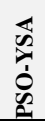 & 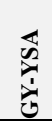 & 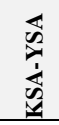 & 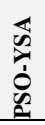 & 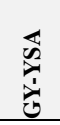 & $\begin{array}{l}\overrightarrow{0} \\
\frac{1}{d} \\
\hat{x}\end{array}$ & $\begin{array}{l}\overrightarrow{0} \\
0 \\
0 \\
0\end{array}$ & 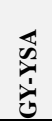 & 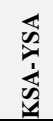 & 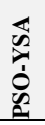 & 嶽 & 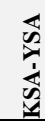 & $\begin{array}{l}\not{D} \\
0 \\
0 \\
0 \\
0\end{array}$ & 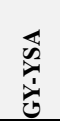 & 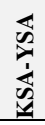 & $\begin{array}{l}\overleftrightarrow{0} \\
0 \\
0 \\
0 \\
0\end{array}$ & 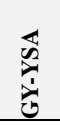 & 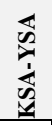 \\
\hline$\sum^{5}$ & ד્ర్ & $\begin{array}{l}\infty \\
\infty \\
\infty \\
\dot{\infty}\end{array}$ & $\begin{array}{l}\text { f } \\
\text { ḋ } \\
\text { i }\end{array}$ & $\stackrel{\Xi}{\Xi}$ & 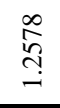 & 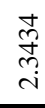 & $\stackrel{0}{0}$ & ڤ̆ & $\begin{array}{l}\text { fo } \\
\text { b } \\
i\end{array}$ & $\begin{array}{l}\text { 卓 } \\
\text { o. } \\
0 \\
0\end{array}$ & 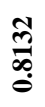 & $\frac{F}{\stackrel{F}{m}}$ & 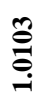 & ڤ્ڤ & 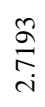 & 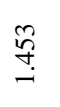 & 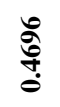 & $\begin{array}{l}\infty \\
\stackrel{2}{2} \\
\stackrel{-}{-}\end{array}$ \\
\hline$\frac{1}{2}$ & $\hat{\hat{o}}$ & $\begin{array}{l}\text { స్ర } \\
\text { i }\end{array}$ & $\begin{array}{l}\vec{t} \\
\overrightarrow{0} \\
\vec{d}\end{array}$ & 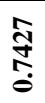 & $\begin{array}{l}\text { t. } \\
\text { ñ. } \\
0\end{array}$ & 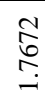 & $\begin{array}{l}\widetilde{\pi} \\
\stackrel{0}{0} \\
\stackrel{6}{8}\end{array}$ & : & స్ & 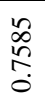 & 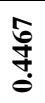 & $\begin{array}{l}\stackrel{8}{0} \\
\stackrel{i}{i}\end{array}$ & 产 & 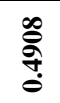 & 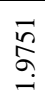 & 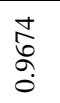 & 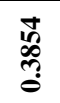 & $\begin{array}{l}\stackrel{8}{8} \\
\stackrel{8}{g}\end{array}$ \\
\hline$\approx$ & $\stackrel{\text { ô }}{\circ}$ & $\frac{+}{\Delta}$ & 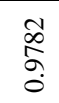 & ڤ̆ & $\begin{array}{l}\text { مू } \\
\text { à }\end{array}$ & 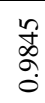 & $\begin{array}{l}0 \\
\text { S. } \\
\text { S. }\end{array}$ & 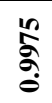 & 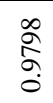 & $\begin{array}{l}\text { ô. } \\
\text { Oे }\end{array}$ & $\begin{array}{l}\bar{\sigma} \\
\text { ô } \\
\text { of }\end{array}$ & $\begin{array}{l}0 \\
\frac{0}{3}\end{array}$ & 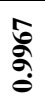 & 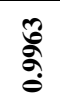 & 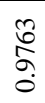 & $\begin{array}{l}\text { वे } \\
\text { gे }\end{array}$ & $\begin{array}{l}\text { t. } \\
\text { S. }\end{array}$ & $\begin{array}{l}+ \\
\stackrel{0}{\circ} \\
\stackrel{0}{0}\end{array}$ \\
\hline
\end{tabular}

Tablo 10. Aralık 2015 Tüm paneller için elde edilen sonuçların karşılaştırılması.

\begin{tabular}{|c|c|c|c|c|c|c|c|c|c|c|c|c|c|c|c|c|c|c|}
\hline & \multicolumn{3}{|c|}{$10^{\circ}$} & \multicolumn{3}{|c|}{$20^{0}$} & \multicolumn{3}{|c|}{$30^{\circ}$} & \multicolumn{3}{|c|}{$40^{\circ}$} & \multicolumn{3}{|c|}{$5 \mathbf{5 0}^{\circ}$} & \multicolumn{3}{|c|}{$60^{0}$} \\
\hline & 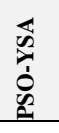 & 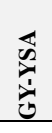 & 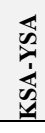 & 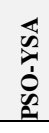 & 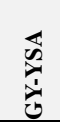 & 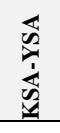 & $\begin{array}{l}\overleftarrow{n} \\
0 \\
0 \\
0 \\
0\end{array}$ & & 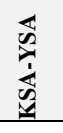 & $\begin{array}{l}\text { 令 } \\
0 \\
0 \\
0\end{array}$ & 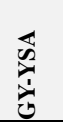 & 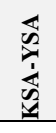 & $\begin{array}{l}\overleftrightarrow{0} \\
0 \\
0 \\
0\end{array}$ & 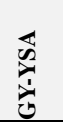 & 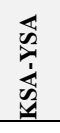 & 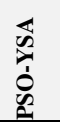 & 芇 & 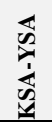 \\
\hline$\frac{1}{\frac{1}{2}}$ & 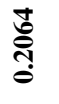 & 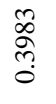 & 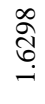 & $\stackrel{\infty}{\pi}$ & $\begin{array}{l}\stackrel{8}{0} \\
\stackrel{0}{q} \\
0\end{array}$ & $\begin{array}{l}\infty \\
\infty \\
\infty \\
\infty \\
\end{array}$ & 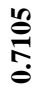 & $\begin{array}{l}\frac{g}{d} \\
\text { ô }\end{array}$ & $\begin{array}{l}\text { సે } \\
\text { ડे }\end{array}$ & 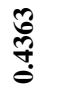 & 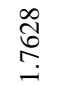 & $\begin{array}{l}\approx \\
\stackrel{0}{0} \\
\stackrel{i}{i}\end{array}$ & ב̃ & 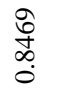 & 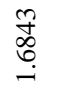 & $\begin{array}{l}\text { క్ } \\
\text { کิ }\end{array}$ & 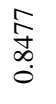 & 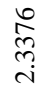 \\
\hline$\sum_{\underline{\pi}}^{2}$ & 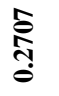 & 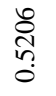 & $\begin{array}{l}\stackrel{\alpha}{\alpha} \\
\text { a }\end{array}$ & $\begin{array}{l}\text { in } \\
\stackrel{\sigma}{g} \\
\stackrel{0}{0}\end{array}$ & $\begin{array}{l}8 \\
\stackrel{8}{0} \\
\stackrel{0}{0}\end{array}$ & $\begin{array}{l}\text { Oे } \\
\hat{b} \\
\text { in }\end{array}$ & ֶֻ. & $\begin{array}{l}\frac{\pi}{\sqrt{n}} \\
\text { n. }\end{array}$ & 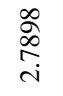 & 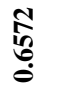 & $\begin{array}{l}\text { ત્ડ } \\
\text { ה }\end{array}$ & $\underset{\hat{\sigma}}{\vec{\lambda}}$ & 䍃 & 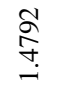 & 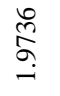 & 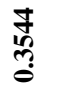 & 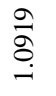 & $\begin{array}{l}\stackrel{\infty}{ } \\
\text { స్j } \\
\text { in }\end{array}$ \\
\hline$\approx$ & 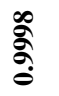 & $\begin{array}{l}\text { ठू } \\
\text { مे }\end{array}$ & $\begin{array}{l}\text { S. } \\
\stackrel{0}{0} \\
0\end{array}$ & O̊. & $\begin{array}{l}\text { Q. } \\
\text { aे }\end{array}$ & $\begin{array}{l}\overline{1} \\
\stackrel{\infty}{0} \\
\stackrel{0}{0}\end{array}$ & $\begin{array}{l}\text { oे } \\
\text { o. }\end{array}$ & \begin{tabular}{l}
$\infty$ \\
\multirow{\alpha}{\alpha}{} \\
0
\end{tabular} & 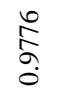 & बे. & $\begin{array}{l}\mathscr{b} \\
\infty \\
o \\
0\end{array}$ & 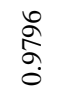 & $\begin{array}{l}\text { ôे } \\
\text { g. }\end{array}$ & $\begin{array}{l}\text { đ̃ } \\
\text { Oे }\end{array}$ & $\begin{array}{l}\stackrel{0}{\circ} \\
\stackrel{0}{\circ} \\
0 \\
0\end{array}$ & : & $\begin{array}{l}\text { ठे. } \\
\text { مे }\end{array}$ & $\begin{array}{l}\frac{\pi}{\infty} \\
\stackrel{\infty}{\circ} \\
\stackrel{0}{0}\end{array}$ \\
\hline
\end{tabular}

\section{Sonuç ve Öneriler}

$\mathrm{Bu}$ çalışmada geriye yayılım algoritmasının yanında iki farklı sezgisel yöntem kullanılarak eğitilen bir YSA modeli ile farklı eğim açılarına $\left(10^{\circ}, 20^{\circ}, 30^{\circ}, 40^{\circ}, 50^{\circ}, 60^{\circ}\right)$ yerleştirilmiş $\mathrm{FV}$ panel güç çıkışlarının, akım ve gerilim değerlerine bağlı olarak aylık olarak tahmin edilmesine yönelik hibrit bir yöntem geliştirilmiştir. Önerilen bu çalışmada, gerçek güç değerleri ile geriye yayılım algoritması yanında PSO ve KSA sezgisel algoritmaları ile elde edilen güç değerlerinin karşılaştırılmalı değerlendirmesi de yapılmıştır. Ayrıca, yöntemin elde edilen sonuçlar üzerindeki etkinliği ölçüm yapılan gerçek ve tahmin edilen değerler arasındaki ortalama yüzdelik hatanın analizi ile doğrulanmıştır.

Çalışmada tahmin sonuçlarının gerçek güç değerleri ile doğrulanmasında, MAPE, RMSE ve $\mathrm{R}^{2}$ istatiksel kriterlerinden yararlanılmıştır. Her üç kriterlerden elde edilen doğrulama sonuçlarına bakıldı̆̆ında, önceki bölümdeki çizelgelerden de görülebileceği üzere hemen hemen tüm aylar için PSO algoritması ile eğitilen YSA yapısının, KSA ve GY algoritmaları ile eğitilen 
YSA yapılarına göre daha başarılı olduğu görülmüştür. Bazı sonuçlarda ise GY ile eğitilen YSA yapısının, PSO ile eğitilen YSA yapısına göre, sonuçlar birbirine yakın olmakla birlikte daha başarılı olduğu anlaşılmıştır. Sonuç olarak deneysel akım ve gerilim değerleri kullanılarak PSO algoritması ile eğitilen YSA'nın güç tahmin sonuçlarının gerçek güç değerleri benzer eğilimler gösterdiği görülmüştür.

Çalışmada ağın öğrenme aşamasında kullanılan algoritmaların, aynı zamanda aylık ortalama güç çıkışlarının tahmin edilmesi için harcanan çalışma süreleri de karşılaştırılmıştır. PSO tabanlı YSA ile aylık ortalama güç çıkışının tahmini ortalama 1.52 saniye sürerken, GY tabanlı YSA ile ortalama 1.48 saniye ve KSA tabanlı YSA ile ortalama 2.01 saniye sürdüğü hesaplanmıştır.

Bundan sonraki aşamada ağa verilecek girdi sayısının artırılması, güneş ışınım verisi gibi ek giriş parametrelerin ölçülmesi, tahmin başarımını artırma yönünde etki edecektir.

\section{Teşekkür}

Yazarlar, bu çalışmada kullanılan güneş paneli verilerinin elde edilmesini sağlayan, deney düzeneğini kuran ve verilerin kullanılmasına izin veren Parmaksiz vd. [3] çalışmasının yazarlarına sonsuz şükranlarını sunmaktadır.

\section{Kaynakça}

1. Theodoropoulos, K., et al. (2017). Monthly Electricity Statistics. International Energy Agency, (https://www.iea.org/media/statistics/surveys/electricity/mes.pdf).

2. Engin, S., Gülersoy, t. (2018). Hibrid Güç Sistemleri İçin Evirici Tasarımı, Avrupa Bilim ve Teknoloji Dergisi, 14, pp. 228-234.

3. Parmaksiz, H., Karafil A., Özbay H., Kesler M. (2016). Farklı Eğim Açılarındaki Fotovoltaik Panellerin Elektriksel Ölçümlerinin Raspberry Pi ile İzlenmesi, Düzce Üniversitesi Bilim ve Teknoloji Dergisi, 4(2),pp. 711-718.

4. Lorenz, E., Hurka, J., Heinemann, D., et al. (2009). Irradiance forecasting for the power prediction of grid-connected photovoltaic systems, IEEE Journal of Selected Topics in Applied Earth Observations and Remote Sensing, 2(1),pp. 2-10.

5. Kudo, M., Nozaki, Y., Endo, H. (2009). Forecasting electric power generation in a photovoltaic power system for an energy network. Electrical Engineering in Japan, 167(4), pp. 16-23.

6. Junseok, S., Krishnamurthy, V., Kwasinski, A., et al. (2012). Development of a Markov-Chain-Based Energy Storage Model for Power Supply Availability Assessment of Photovoltaic Generation Plants, IEEE Transactions on Sustainable Energy, 4(2), pp. 491-500.

7. Li, Y., Niu, J., (2009). Forecast of power generation for grid-connected photovoltaic system based on Markov chain, Power and Energy Engineering Conference, APPEEC 200, Asia-Pacific. 1-4.

8. Ran, L., Guang-min, L. (2008). Photovoltaic power generation output forecasting based on support vector machine regression technique, CNKI Journal of Electric Power, 2, 031.

9. Shi, J., Lee, W. J., Liu, Y., et al. (2012). Forecasting Power Output of Photovoltaic Systems Based on Weather Classification and Support Vector Machines, IEEE Transactions on Industry Applications, 48(3), pp. 1064-1069.

10. Wang, F., Mi, Z., Su, S., Zhang, C. (2011). A practical model for single-step power prediction of grid-connected PV plant using artificial neural network, Innovative Smart Grid Technologies Asia (ISGT), pp. 1-4.

11. Kou, J., et al. (2013). Photovoltaic power forecasting based on artificial neural network and meteorological data, TENCON 2013-2013 IEEE Region 10 Conference, Xian, China.

12. Zhang, N. et al. (2013). Solar Radiation Prediction Based on Partıcle Swarm Optimization and Evolutionary Algorithm Using Recurrent Neural Networks, IEEE Annual System Conference.

13. Qasrawi, I., Awad, M. (2015). Prediction of the Power Output of Solar Cells Using Neural Networks: Solar Cells Energy Sector in Palestine, International Journal of Computer Science and Security (IJCSS), 9(6), pp. 280.

14. Zhu, H., Li, X., (2016). A Power Prediction Method for Photovoltaic Power Plant Based on Wavelet Decomposition and Artificial Neural Networks", Energies, 9(1), pp. 11.

15. Prokop, L.,et al. (2012). Photovoltaic Power Plant Output Estimation by Neural Networks and Fuzzy Inference, IDEAL 2012, pp. 810-817.

16. Paulin, B.J., Praynlin, E. (2016). Solar Photovoltaic Output Power Forecasting Using Back Propagation Neural Network, ICTACT Journal on Soft Computing, 6(2).

17. Rana M., et. al. (2015). Forecasting Solar Power Generated by Grid Connected PV Systems Using Ensembles of Neural Networks, International Joint Conference on Neural Networks (IJCNN), Ireland.

18. Kahramanli, H., Allahverdi, N. (2008). Design of a hybrid system for the diabetes and heart diseases, Expert Systems with Applications, 35 (1), pp. 82-89.

19. Franklin, S.W., Rajan, S., Computerized screening of diabetic retinopathy employing blood vessel segmentation in retinal images, Biocybernetics and Biomedical Engineering, 34 (2), pp. 117-124.

20. Haykin, S., (2004). A comprehensive foundation, Neural networks, 2, pp. 41.

21. De Castro, L.N., Von Zuben, F.J. (2002). Learning and optimization using the clonal selection principle, Evolutionary Computation, 6(3), pp. 239-251.

22. Gao, X.Z. (2009). Clonal optimization-based negative selection algorithm with applications in motor fault detection, Neural Computing and Applications, 18(7), pp. 719-729. 